UNIVERSITÀ CATTOLICA DEL SACRO CUORE

Dipartimento di Economia e Finanza

\author{
Working Paper Series
}

Who do you blame in local finance? An analysis of municipal financing in Italy

Massimo Bordignon, Veronica Grembi, Santino Piazza

Working Paper n. 35

December 2015

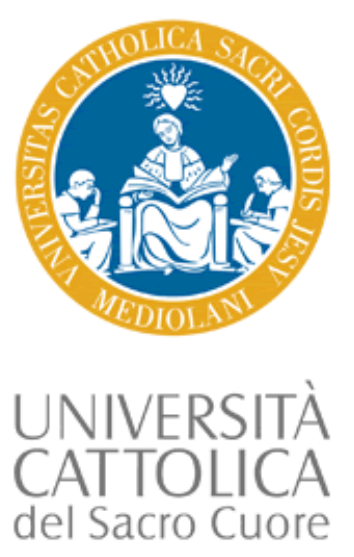




\title{
Who do you blame in local finance? An analysis of municipal financing in Italy
}

\author{
Massimo Bordignon \\ Università Cattolica del Sacro Cuore \\ Veronica Grembi \\ Università Cattolica del Sacro Cuore
}

Santino Piazza

IRES, Piemonte

Working Paper n. 35

December 2015

\author{
Dipartimento di Economia e Finanza \\ Università Cattolica del Sacro Cuore \\ Largo Gemelli 1 - 20123 Milano - Italy \\ tel: +39.02.7234.2976 - fax: +39.02.7234.2781 \\ e-mail: dip.economiaefinanza@unicatt.it
}

The Working Paper Series promotes the circulation of research results produced by the members and affiliates of the Dipartimento di Economia e Finanza, with the aim of encouraging their dissemination and discussion. Results may be in a preliminary or advanced stage. The Dipartimento di Economia e Finanza is part of the Dipartimenti e Istituti di Scienze Economiche (DISCE) of the Università Cattolica del Sacro Cuore. 


\title{
Who do you blame in local finance? An analysis of municipal financing in Italy*
}

\author{
Massimo Bordignon†, Veronica Grembi ; Santino Piazza ${ }^{\S}$
}

\begin{abstract}
In a political agency model, we study the effect of introducing a less transparent tax tool for the financing of local governments. We show that lower quality politicians would use more the less transparent tax tool to enhance their probability of re-election. This prediction is tested by studying a reform that in 1999 allowed Italian municipalities to partially substitute a more accountable source of tax revenue (the property tax) with a less transparent one (a surcharge on the personal income tax of residents). Using a Difference in Difference approach, we show that in line with theory, Mayors at their first term in power adopted a higher surcharge on the personal income tax and reduced the property tax rate significantly more than Mayors in their final term.
\end{abstract}

Keywords: Fiscal federalism, Tax transparency, Agency Model, Property tax. JEL Classification: H71, H77, D78.

*We are thankful for their comments on previous and preliminary drafts of this work to two anonymous referees, Albert Solé Ollé, Thiess Buettner, Federico Revelli, Matz Dahlberg, Chiara Dalle Nogare and the participants of the 2009 IEB workshop on Fiscal Federalism, the 2009 IIPF Conference, the 2011 SIEP Conference, and the 2014 Meeting of the European Public Choice Society. The research assistantship of Johannes Odenkirchen is gratefully acknowledged. The usual disclaimer applies.

†Corresponding author massimo.bordignon@unicatt.it. Tel +3902 7234.2976 Fax +39027234.2781. Catholic University of Milan, Department of Economics and Finance; CESIFO, Munich, Germany.

$\ddagger$ Copenhagen Business School; CIFREL, Catholic University of Milan; CEIS Tor Vergata; Baffi Center, Bocconi University.

$\S$ I.R.E.S. Piemonte - Socioeconomic Research Institute of Piedmont. 


\section{Introduction}

Traditional claims in favor of fiscal decentralization support better representation of local preferences and better accountability of local politicians (Lockwood, 2006). Yet, skepticism remains. An interesting and well-founded objection is that decentralization is not akin to separation; in a unitary State, even when decisions on important public services are delegated to local governments, financing often largely remains in the hands of the central government (see Ambrosanio and Bordignon, 2006; Boadway, 2006). According to critics, this implies that decentralization may weaken, rather than strengthen, political accountability, leading to less efficient equilibria (e.g., Devarajan et al., 2007). Intuitively, if citizens are uncertain about whom to blame for the taxes they have to pay, they will be less able to punish or reward the right politicians for their behavior. In turn, this will lead to more leniency in the provision of public services. Accordingly, it is financing and the transparency of local taxes, more than decentralization per sé, that are key ingredients of a successful decentralization process.

Given its policy relevance, it would be clearly important to assess the validity of this claim. Doing this in general terms may be difficult, but one can learn from specific real world examples. This is what we do in this paper, by focusing on an important local finance reform in the Italian context. In 1999, following a decade of decentralization, it was decided to offer Italian municipalities an additional source of tax revenue, allowing them to levy a surcharge on their residents' personal income tax (PIT) base, which is the most important national tax. This surcharge was to accompany the traditional source of tax revenue for cities (since 1993), that is a property tax (ICI) raised on the municipality housing wealth, with slightly different rules for the house of residence of taxpayers (where selective deductions could also be offered) and commercial buildings (where only the tax rate could be varied). However, there was an important difference between the two tax tools. While the decisions concerning the property tax could clearly and unambiguously be attributed to the municipal government, this was not the case for the PIT surcharge. Central government maintained its full powers on PIT, including the definition of tax rates, tax base and tax brackets - all features that are usually marginally altered on a yearly basis by the central government. Municipal governments could only raise a flat surcharge on their PIT base, by $0.2 \%$ yearly up to a total of $0.5 \%$ in three years. In contrast, the average central government tax rate on the PIT base was about $20 \%$ in our sample in the same period. As a result, citizens might have had some difficulty in discerning in the total PIT they had to pay, the part which was due to municipal decisions -and maybe even few incentives to learn it, given its small share on the total. ${ }^{1}$ On the contrary, the property tax rate was independently paid directly by each house owner to the municipality where the estate was located. This task required each taxpayer to get informed about the property tax rate and the tax allowance, which are usually set up and changed on

\footnotetext{
${ }^{1}$ It is true that the municipal surcharge rate is indicated in the PIT tax form of each tax payer. But, as a matter of fact, most Italians never actually come to see their tax bill. For dependent workers, the PIT, including the municipal surcharge tax, is directly withheld by the company they work for on a monthly base; and most self-employers also use tax professionals to fill properly their tax forms.
} 
a yearly basis by municipal governments. ${ }^{2}$

Based on this, it is plausible to assume that the municipal surcharge on the PIT national base was for most citizens less "transparent" than the municipal property tax, in the sense of allowing for a less precise attribution of responsibility to the different levels of government (e.g. Bordignon and Minelli, 2001). ${ }^{3}$ Going back to the previously mentioned literature, this would suggest that the political incentives for using the two different taxes may also have been different. In the next section, with the aim to uncover these different incentives, we set up a simple agency model of politics (Besley, 2007). In order to provide guidance to the empirical analysis, the model is designed by having the Italian tax reform in mind, but its insights are clearly more general. Thus, in the model, municipal politicians (i.e. "Mayors" from now on) may be of two types; competent or incompetent. Incompetent Mayors can replicate the fiscal decisions of competent Mayors, but at a higher cost in terms of effort. The economy lasts two periods, an assumption that captures a important feature of Italian municipal governments as Mayors are subject to a term limit (they can only run twice; see section 3). Lacking electoral incentives, incompetent Mayors would then raise more taxes and exert less effort than competent ones. However, in their first term in power, incompetent Mayors may nevertheless prefer to imitate the efficient ones, in the hope that this will result in a re-election, because citizens cannot directly observe the type of Mayor, but only try to infer it by observing his tax choices. Using this simple model, we then study political equilibria in the two cases, when Mayors can only use the property tax and when they can use both the property tax and the tax surcharge on PIT. Importantly, in the latter case we assume that citizens are unable to discern precisely which part is played by which level of government in setting up the total PIT tax rate. We show that pooling equilibria are more likely to occur after the reform than before it. In equilibrium, incompetent Mayors make a larger use of the surcharge rate on PIT, which can only be imperfectly observed by citizens, as this offers them a less costly way to imitate the competent local governments.

Several empirical implications derive from these theoretical observations. The one we can test is that first term Mayors should use on average the less transparent tax tool more than second term Mayors, as the former have stronger electoral incentives. We test this prediction on a unique dataset of 7,583 Italian municipalities in the period 1995-2005. We

2 "Proving" that the PIT surcharge was less visible to taxpayers is obviously difficult, but one can at least invoke some anecdotal supporting evidence. For instance, an online research on the Italian national newspaper with the largest number of local editions (La Stampa) in the period 1999-2006, returned 5736 hits for the the term ICI (Local Property Tax), 2743 for the term IRPEF (national PIT) and only 658 for the term addizionale comunale sul reddito (PIT surcharge) (details available from the authors on request), suggesting that press coverage for the latter was much more limited than for the other two. Similarly, according to a survey by Censis (2010:11), Italians consider three local taxes as the most hateful taxes (the Local Property Tax is in the third position) with the national PIT in the fifth one. However, the PIT surcharge is not even mentioned in this ranking.

${ }^{3}$ Alternatively, one could argue that the property tax is "salient" for taxpayers (Chetty et al., 2009), while for some reasons, they do not pay the same attention to the income tax. The predictions of our model would be the same in both cases (incompetent politicians would use more of the no salient tax) but the normative implications for the fiscal federalism literature would be different. We come back to this in the conclusions, after having discussed our empirical results. 
use a Difference-in-Difference approach to identify the effect of the introduction of the less transparent tax tool on the tax choice of Mayors, defining the treated Mayors as those that are up for re-election. To avoid unobservable differences between Mayors who were or were not re-elected, our baseline specification is tested on a sample of municipalities in which all Mayors completed two terms, so that the same individuals are compared across two terms. The results accord well with theory. After the introduction of the PIT surcharge, eligible Mayors reduced the property tax rate on commercial buildings by almost one percentage point $(1.4 \%$ at the mean of property tax $)$ more, and increase deductions on the property tax on residence houses by $11 \%$ more, than Mayors at their final term, and adopted a PIT surcharge higher by $20 \%$. These results are robust to the inclusions of several controls and were not driven by anticipatory effects. Furthermore, a number of tests corroborates our political economy story. In particular, it turns out that the reduction in the property tax is larger in localities where one would have expected to find less political accountability to start with, that is in municipalities with lower level of social capital and less information on municipal policies as provided by the local press.

Our empirical results then support the idea that transparency in local taxation is a crucial factor for political accountability. This is an important insight for the fiscal federalism literature as many countries use surcharge taxes on national taxes as a less costly way to raise revenue at local level (Shah, 2006). The possible inefficiency arising from more levels of government insisting on the same tax base has already been stressed by the literature on vertical tax externalities (e.g. Keen, 1998; Boadway et al., 1998), but the political effect in terms of a possible reduction of accountability for local governments has been less discussed (but see Cabral and Hoxby, 2012 and Norregaard, 2013 for similar insights). On theoretical grounds, version of our own idea have already been proposed (Besley, 2007) and applied to different outcomes such as the observability of government reporting procedures (Milesi-Ferretti, 2000), government's choice between taxes and debt (Alt and Dreyer Lassen, 2003), the hidden financing of interest groups (Coate and Morris, 1995), the trade off between accountability and efficiency (Bordignon and Minelli, 2001), and the political economic budget cycle (Rogoff et al. 1988), among others. But, to the best of our knowledge, we are the first to attempt to provide a direct test of the idea, by comparing the tax choices of local governments before and after a reform which directly affects the transparency of their tax tools. Tax setting in Italian municipalities have already been analyzed by several other authors (Bordignon et al., 2003; Bordignon et al., 2014; Grembi et al., 2012), but with a different focus. The closest study to ours is a recent work by Bracco et. al, (2013), who argue that local governments that are subject to stronger political incentives should rely more on tariffs and less on taxes. They found support for this prediction in their empirical analysis of Italian municipalities. Their explanation is based on behavioral distortions (taxes are more visible to voters because they are paid in larger installments rather than in continuously small sums, as with tariffs as shown in Klien(2014)), but their results could also be rationalized in terms of transparency of the different means of financing.

The rest of the paper is organized as follows. Section 2 sketches the model and lays out our main theoretical results. Section 3 derives and summarizes the main empirical prediction of the model. Section 4 describes the data set and explains in more detail the Italian institutional 
setting. Section 5 presents our empirical strategy, the main results, and their robustness checks, and Section 6 concludes. Online Appendix 1 presents in more detail the model and proves the main propositions, while Online Appendix 2 defines more precisely the variables we use in the empirical analysis.

\section{Theoretical framework}

To motivate the empirical analysis, we sketch here the results of a simple agency model that captures the idea of lack of political accountability induced by less transparent fiscal tools (see Appendix 1 for a more complete analysis). Consider then a local economy with a large number of identical voters. The representative voter in this economy has utility function:

$$
u=U(h)+c+V(1-l)
$$

where $h$ is housing services, $c$ private consumption, $l$ labor supply and $U(),. V($.$) are both$ increasingly and strictly concave functions, differentiable to any required order. Buying a house is costly, but we assume consumers expect some future capital gains from investing in housing, in addition to current housing services. Let $r<1$ indicate the present net value of these returns for each unit of housing bought. Local property taxation has the effect of reducing these net returns. The voter is also taxed on her (labor) income. Normalizing units so that buying one unit of housing costs one unit of numeraire, and also assuming that the (fixed) wage rate is one, the voter's budget constraint is:

$$
c+(1-(1-\tau) r) h=(1-\theta) l
$$

where $\tau$ is the local property tax and $\theta$ the income tax. Solving voter's maximizing problem, and assuming interior solutions, we obtain the voter's demand functions:

$$
h^{*}=H(\tau)
$$

and

$$
l^{*}=L(\theta)
$$

Note that separability implies that each demand is a function of its net of tax price only, while strict concavity implies $H^{\prime}(\tau)<0$ and $L^{\prime}(\theta)<0$. For future reference, let $\varepsilon^{h}=$ $-\tau H^{\prime}(\tau) / H(\tau)$ and $\varepsilon^{l}=-\theta L^{\prime}(\theta) / L(\theta)$ be the corresponding price elasticities.

The local community is governed by a policy maker, hereafter Mayor, whose utility is given by

$$
w=u+E-\frac{s}{2} e^{2}
$$

where $u$ is the utility of the representative voter, $E>0$ is an exogenous utility derived from the pleasure of being in office ("ego rents", including any monetary benefits from holding office), and $e$ is the "effort" that the Mayor makes in order to improve the efficiency of public 
services. That is, local policy makers are benevolent, but also like being in office and dislike having to make an effort. The marginal disutility of effort depends on a parameter $s$, with a higher $s$ implying a higher utility loss for a given level of effort. Potential policy makers differ in the parameter $s$. For simplicity, we assume that there are only two types of Mayors, a "competent" one, with marginal disutility of effort given by $\underline{s}$ and an "incompetent" one , with marginal disutility given by $\bar{s}$, where $\bar{s}>\underline{s}>0$. We also assume that $e \geq 0$, that basically means that a Mayor cannot cash the local tax revenue for private consumption.

Policy makers, when in office, need to offer a fixed amount of per capita public services (i.e., public goods), entering separately in the utility function of consumers, which we normalize to a unit. Letting $R$ indicate per capita local tax revenue, local government's budget constraint can then be written as

$$
1=R+e
$$

Hence, effort $e$ is here introduced as a (partial) substitute for tax revenue; a larger effort level improves the efficiency of local administration and thus reduces the amount of tax revenue needed to provide the given amount of public services. $R$ can have various interpretations, as discussed below.

\subsection{Benchmark analysis}

As a benchmark case, suppose first that the economy lasts one period only and that the Mayor can only use the property tax (the income tax is set by the central government). A Mayor of type $s$, when in charge, would then choose $\tau$ and $e$ so as to maximize his utility function in equation 5 subject to the budget constraint in equation 6 . Substituting for $h^{*}$ and $l^{*}$ in the utility of the consumer, substituting the consumer's indirect utility in the welfare function of the local politician and solving, we obtain the following FOC for the Mayor's optimal problem ${ }^{4}$ :

$$
r=s\left(1-\tau^{*} H\left(\tau^{*}\right)\right)\left(1-\varepsilon^{h}\left(\tau^{*}\right)\right)
$$

By totally differentiating the FOC, it is easy to check that $d \tau^{*} / d s>0$. As $\varepsilon^{h}\left(\tau^{*}\right)<1$ at the optimum, this also implies from equation 6 that $d e^{*} / d s<0$. Intuitively, incompetent Mayors would provide less effort in equilibrium and therefore tax voters more than competent ones. To emphasize this point, let us rewrite the optimal decisions of Mayors as a function of $s ; \tau^{*}(s), e^{*}(s)$. Our previous discussion therefore implies $\tau^{*}(\bar{s})>\tau^{*}(\underline{s})$ and $e^{*}(\bar{s})<e^{*}(\underline{s})$.

\subsection{Two periods with asymmetric information}

To provide governments with electoral incentives, let us now instead assume that there are two periods. In the first period, after the central government has set $\theta$, the incumbent Mayor sets up $\tau$ and $e$. Voters subsequently make their choices about $h$ and $l$. At the end of the

\footnotetext{
${ }^{4} \mathrm{~A}$ sufficient condition for the SOC to be satisfied is that $\varepsilon_{\tau}^{h}\left(\tau^{*}\right) \geq 0$, we assume this to be the case
} 
first period, an election takes place and voters either re-elect the incumbent or an opposing candidate. In the second period, whoever is in charge sets again $\tau$, and voters choose again $h$ and $l$. The game ends there. Thus, the two periods are identical, except for the fact that at the end of the first period there is an election. The voter does not observe the type of Mayor or his level of effort, but she observes the tax rates she has to pay. Voters do, however, expect politicians - both the incumbent policy maker and the opponent- to be competent with probability $q \in(0,1)$. The Mayors instead know their type. What would then be the choices of the two types of government and of the voters?

To answer this question, we look at the Bayesian perfect equilibria of this game; that is, equilibria where each agent's strategy is optimal given the strategies of any other agent and given his beliefs about any other agent's type, and where beliefs, whenever possible, are derived according to Bayes' rule. To solve the model, we work backwards. In the second period, as there is no future period, each Mayor would select his favorite options; i.e. $\tau^{*}(s)$, $e^{*}(s)$, for $s=(\bar{s}, \underline{s})$. But in the first period, the incompetent Mayor may attempt to exploit his superior knowledge in order to convince the voter that he is competent and then be re-elected. Assume, as customarily done in this literature (e.g. see Besley, 2007) that the competent Mayor does not play strategically and just select $\tau^{*}(\underline{s}), e^{*}(\underline{s})$ in both periods. ${ }^{5}$ This allows us to fix out-of-equilibrium beliefs in a very convenient way, as this assumption implies that if the rational voter observed in the first period anything different from $\tau^{*}(\underline{s})$, she would immediately understand that the incumbent Mayor is incompetent and thus vote for the opposing candidate in the ensuing elections.

In turn, this implies that the incompetent Mayor has really only two strategies to play in the first period (any other strategy is strictly dominated by one of these two). He can either play his preferred strategy, setting $\tau^{*}(\bar{s})$ in the first period, save effort and accept defeat in the elections. Or he can mimic the competent type, play $\tau^{*}(\underline{s})$, select $e$ appropriately to satisfy equation 6 , and hope that this will result in re-election. Which is the optimal strategy for the incompetent Mayor clearly depends on the cost of imitating the competent Mayor in the first period (that is, playing $\tau^{*}(\underline{s})$ rather than his optimal strategy $\tau^{*}(\bar{s})$ ) and on the expected benefit in terms of higher probability of re-election, that also depends on the discount factor $\delta \in(0,1)$ on future utility. Appendix 1 shows that what the incompetent Mayor does, it depends on an endogeneously determined threshold, $0<k_{1}<1$ : ${ }^{6}$

Proposition 1 Consider a two period economy, where local governments can only select the property tax. If $\delta \geq k_{1}$ there exists a pure strategy fully pooling equilibrium, in which the incompetent Mayor mimics the competent one in the first period, setting $\tau^{*}(\underline{s})$, $e^{*}(\underline{s})$ in this period. At this pooling equilibrium, both types of Mayor are re-elected. If instead $\delta<k_{1}$ there exists a pure strategy separating equilibrium in which each type of government selects his favorite strategy in the first period (e.g. the incompetent Mayor plays $\tau^{*}(\bar{s}), e^{*}(\bar{s})$ in the

\footnotetext{
${ }^{5}$ The equilibrium we describe would still exist even if competent Mayors behaved strategically; however, it would not be unique. See the technical discussion in Besley(2007).

${ }^{6}$ The proposition assumes that when indifferent the voter votes for the incumbent. Note that this assumption also rules out mixed strategy equilibria. See Appendix 1.
} 
first period). At this equilibrium, the competent Mayor is re-elected, while the incompetent Mayor is defeated at the elections.

where $k_{1}$ can be shown to be strictly increasing in the difference between $(\bar{s}-\underline{s})$ and strictly decreasing in the exogenous utility for holding office, $E$. Intuitively, it will be then more likely to observe pooling equilibria the smaller the difference in productivity between competent and incompetent Mayors, the more policy makers care about being in office, and the more they care about the future.

\subsection{A local surcharge on the income tax}

How do these conclusions change when, besides the property tax, a local surcharge on the income tax is also offered to local politicians? Suppose that the total income tax is now the sum of a central tax rate $T$ and a local surcharge one $t$, so that $\theta=T+t$, and that the central government moves first and the local government moves later, having observed the $T$ chosen by the central government. Repeating the previous analysis and solving for the two types of Mayor's optimizing problem in the second period (when there are no electoral incentives), under the new budget constraint $1=\tau H(\tau)+t L(T+t)+e$, one would still get the preferred choices for the two types of governments, now written as a function of $T$ too, $\tau^{*}(s, T), t^{*}(s, T), e^{*}(s, T)$. Again, one can easily show that $\tau^{*}(\bar{s}, T)>\tau^{*}(\underline{s}, T), t^{*}(\bar{s}, T)>$ $t^{*}(\underline{s}, T)$ and $e^{*}(\bar{s}, T)<e^{*}(\underline{s}, T) .^{7}$

Clearly, maintaining all our other assumptions equal, our conclusions in Proposition 1 would not qualitatively change if we also assumed that the voter too could observe $T$ (since she observes $\theta$ and therefore can compute $t$ ). Again, the incompetent Mayor would only have the choice of fully imitating the competent Mayor's decisions (e.g. playing $t(\underline{s}, T)$ and $\tau(\underline{s}, T))$ in the first period and being re-elected, or deviate, playing his preferred strategy $(t(\bar{s}, T)$ and $\tau(\bar{s}, T))$ and then being defeated at the elections.

But suppose now that the voter cannot observe either $T$ or $t$, but only their sum, $\theta$ as implied by our discussion above for the Italian case. This would then offer the incompetent Mayor a second strategy for pooling; he can now use his superior knowledge about the move of the Central government to pretend that a different $T$ has been chosen, and use the extra revenues collected from the income tax to reduce the effort he has to make in order to imitate the competent Mayor. Intuitively, this might make pooling easier.

More specifically, suppose, for simplicity, that the Central government can only make two tax choices, $\bar{T}$ or $\underline{T}$, where $\bar{T}>\underline{T}>0$, and that the voter expects the Central government to set in the first period the higher tax rate $\bar{T}$ with probability $\pi \geq \frac{1}{2} \cdot{ }^{8}$ Let us define a partial

${ }^{7}$ This requires $\varepsilon_{\theta}^{l}(\theta)>0$ and $\varepsilon_{\tau}^{h}\left(\tau^{*}\right)>0$ that are also sufficient conditions for the SOC in the mayors' optimizing problems to be satisfied. See Appendix 1.

${ }^{8}$ As an interpretation, one may think that the central government needs to supply a separate (not modeled here) national public good and that the cost of providing this public good is subject to a technological shock, with a negative shock occurring with ex ante probability $\pi$. Assuming that the central government is benevolent and that it does not care for Mayor choices, it will then set up a high tax rate when the shock is negative and a low tax rate when the shock is positive. If the shock is not observable by citizens, we then get the situation described in the model. 
pooling strategy for the incompetent Mayor as one where, while the Central government played $\underline{T}$, the incompetent Mayor pretends instead that $\bar{T}$ was played, and set his first period choices so as the determine the observable tax rates, $\tau$ and $\theta$, at the same level that would occur if indeed the Central government had played $\bar{T}$ and he, the incompetent Mayor, was competent: that is, the incompetent Mayor sets $\tau(\underline{s}, \bar{T})$ and $\widetilde{t}=\bar{T}-\underline{T}+t(\underline{s}, \bar{T})$ in the first period. Observe that this offers a benefit to the incompetent Mayor in the first period, because he can now use the extra revenues from the income tax to satisfy the budget constraint with a lower level of effort (see Appendix 1). Of course, at the equilibrium, the rational consumer would expect the incompetent Mayor to play this strategy when $T=\underline{T}$, but as $\pi \geq \frac{1}{2}$, by Bayes' rule, upon observing $\tau(\underline{s}, \bar{T})$ and the corresponding level for $\theta$, the voter would rationally conclude that it is more likely that these choices come from a competent Mayor facing $\bar{T}$, and then re-elect him. Finally, in playing this partial pooling strategy in the first period, rather than his preferred strategy, the incompetent Mayor incurs a cost; but one can show (see Appendix 1) that if the two types are sufficiently apart (that is, if $\frac{\bar{s}}{\underline{s}}>\widehat{s}$ ) this cost is however lower than the cost that the incompetent Mayor would incur if instead he played the fully pooling strategy (that is, if he did not lie about $T$ and $\operatorname{set} \tau(\underline{s}, \underline{T})$ and $t(\underline{s}, \underline{T})$ in the first period). This implies that the fully pooling strategy is dominated by the partial pooling strategy when $T=\underline{T}$; it cannot offer the incompetent Mayor a higher probability of re-election and imposes on him a higher cost in the first period.

Collecting all these observations, one can then prove (see Appendix 1 for a more detailed proof):

Proposition 2 Consider a two period economy, where Mayors can select both the property tax and a surcharge on the income tax base. Providing that $\frac{\bar{s}}{\underline{s}}>\widehat{s}$, if the national government selects $\underline{T}$ and $\delta \geq k_{3}(\bar{T})$ there exists a partial pooling equilibrium in pure strategies in which the incompetent Mayor plays in the first period $\tau(\underline{s}, \bar{T})$ and $\widetilde{t}=\bar{T}-\underline{T}+t(\underline{s}, \bar{T})$. If the national government selects $\bar{T}$ and $\delta \geq k_{2}(\bar{T})$ there exists a fully pooling equilibrium in pure strategies, where the incompetent Mayor in the first period chooses $\tau^{*}(\underline{s}, \bar{T}), t^{*}(\underline{s}, \bar{T})$. If the national government selects either $\underline{T}$ and $\delta<k_{3}(\bar{T})$, or $\bar{T}$ and $\delta<k_{2}(\bar{T})$, there exist separating equilibria where the incompetent Mayor only selects his preferred choices in the first period. At both the fully pooling equilibrium and at the partial pooling equilibrium, both types of government are re-elected. At the separating equilibria, the competent Mayor will be re-elected and the incompetent Mayor defeated at the ensuing elections.

\section{Discussion and empirical predictions}

The main theoretical result of this paper is laid out in the following corollary, which is proved in Appendix 1:

Corollary 1 The set of values of $\delta$, that supports pooling equilibria when the move by the central government is observable by citizens is a proper subset of the set of values of $\delta$ that 
supports pooling equilibria when the move by the central government is not observable by citizens.

The corollary is just a consequence of the fact, proved in Appendix 1, that $k_{2}(\underline{T})>k_{3}(\bar{T})$. Intuitively, the surcharge rate on the personal income tax, which can only be imperfectly observed by citizens, offers incompetent Mayors a less costly way to imitate the competent ones, and this is reflected in a larger set of parameters supporting pooling equilibria. Hence, the reduction in accountability induced by the surcharge rate reduces the ability of citizens to distinguish between competent and incompetent local politicians. Finally, note that $k_{1}(T) \geq$ $k_{2}(T)$ is also very likely, as can be shown by a revealed preference argument (laid out in Appendix 1). Our general conclusion is therefore that the introduction of the PIT surcharge should have the effect of increasing pooling behavior, allowing incompetent Mayors to mimic competent ones in a larger set of cases.

On empirical grounds, the model then produces several predictions. One is that we should observe a reduction in the average quality of politicians after the reform. However, this prediction is difficult to test as there is no commonly agreed and observable measure of the quality of politicians, both ex ante or ex post. But there is a second prediction of the model that is instead easily testable with our data. First, observe that we should expect a general reduction of the property tax following the introduction of the surcharge tax on income. This is because even competent Mayors, both in their first and second term, may prefer to use this second tax tool too to finance the given amount of services, thus reducing the property tax. However, as pooling behaviour increases, we should observe (incompetent) Mayors cutting more the property tax and use instead the personal income tax surcharge to increase their probability of re-election. ${ }^{9}$ And this should happen mainly in the first term, as the Mayor has stronger electoral incentives in this term. ${ }^{10} \mathrm{~A}$ testable prediction of the model is therefore that we should observe a larger use of the PIT surcharge and a stronger reduction in the property tax rate for Mayors who are up for re-election. In the following sections, this prediction will be tested.

\footnotetext{
${ }^{9}$ To get this prediction explicitly from our theoretical model is enough to assume that the discount rate has some distribution across the population of Mayors. As $k$ falls following the reform, we should observe more pooling behavior as also incompetent Mayors with a lower discount rate now decide to pool.

${ }^{10}$ This does not mean to deny that there may be other reasons (say, party discipline) that might lead even a second term Mayor to fiscally behave so as to improve the opportunity that his own party is confirmed at the elections. Indeed, as shown below, the presence of a electoral cycle even for second term Mayors confirms this effect. But we assume that the electoral incentives for the Mayor are stronger when he is the one who can be re-elected. This is both intuitive and has already been confirmed in previous analyses on the Italian case (e.g. Bordignon et al. (2003)). See Besley and Case (1995) for the general argument on the use of term limits.
} 


\section{Institutions and Data}

\subsection{Municipal taxes and political institutions}

Municipal finance in Italy has traditionally been characterized by a large share of the financial needs of municipalities being covered by grants from the central government. Because of the several inefficiencies this system created, and in the context of a general reform affecting all sub-national levels of government, several steps were taken in the '90s to increase the tax autonomy of municipalities (Ambrosanio et al., 2006). A local property tax (Imposta comunale sugli immobili, ICI) was introduced in 1993 (legislative decree n.504/1992), with an offsetting reduction in central government transfers, so that at the (compulsory) minimum ICI tax rate a municipality had the same resources both before and after the reform. ${ }^{11}$ Also a personal income tax (PIT) surcharge was added in 1999 (legislative decree n. 360/1998; see below). In 2000, for instance, the property tax constituted approximately $50 \%$ of the total tax revenue of municipalities, while the PIT surcharge was responsible for approximately $8 \%$ of the total tax revenues.

The ICI tax base for each real estate was set up by the national government using the national cadaster. Each municipality was allowed to choose two distinct property tax rates, one called business tax rate (on commercial buildings, but also covering residential buildings different from the main residence of the taxpayer), and the other, the main residence tax rate, which was devoted to the main residence of the taxpayer only. Both property tax rates could vary within a bracket by 0.4 to 0.7 percent of the cadastral value of the property, but resident owners could benefit from deductions on the tax paid on their main residence (see Appendix 2 for a proper definition). In turn, these deductions were freely established by the municipal administration, taking into account, for instance the income, other assets, and the composition of the resident household. Finally, in 2008, the property tax on the main residence of the taxpayer was abolished.

In 1999 the surcharge on the personal income tax base of residents (i.e., PIT surcharge) was offered to municipalities, essentially as a way to provide them with a more elastic source of revenues, given the rigidity of the property tax base, and to further increase their tax autonomy. Notice that the PIT reform did not involve an offsetting reduction in transfers, because the surcharge tax was an opportunity, not an obligation, for municipalities. In the period we analyze, the PIT surcharge was in a bracket of 0 to $0.5 \%$ of taxable income (it was increased up to $0.8 \%$ in 2007). The central government froze the PIT surcharge in 2003 at the rate that had been set by the municipalities, but still allowed municipalities that had not used it before to introduce it. We will come back to this in section 6.3.

Notice that ICI and PIT tax rate decisions for year $t$ are usually made in the last month of the preceding year t-1, when municipalities approve their provisional budget for year $\mathrm{t}$. The central government also usually makes decisions about the personal income tax for year $\mathrm{t}$ at year $\mathrm{t}-1$, with the approval of the budget law for the next year. The national budget law is generally approved in December, but the proposed budget law is presented by the

\footnotetext{
${ }^{11}$ The effect of the reform was huge, and the share of transfers on total municipal revenues dropped by more than $20 \%$ in 1993. See Bordignon et als., 2015 for a discussion.
} 
government to Parliament in September and widely discussed. Thus, in line with the time line assumed in the model, it is reasonable to assume that municipal governments make their decisions concerning their tax rates following the decisions of the central government.

Concerning political institutions, the year 1993 marked another important change; since that year (Law 81/1993), Mayors have been elected directly by citizens, with a bonus that guarantees the political parties supporting the elected Mayor to gain the majority of seats in the municipal Council. The Council can still dismiss the Mayor, but in that case new elections need to take place. The Mayor can also select and dismiss the municipal executive office (Giunta) and choose the head of the municipal administration. Hence, the 1993 electoral reform made the Mayor the paramount figure in municipal policy (see Bordignon et al., 2015 for more details). This supports our focus on Italian Mayors in what follows.

\section{Dataset}

Figure 1 summarizes the main reforms concerning local taxation within the period covered by our dataset: $1995-2005 .^{12}$ We work with a panel of 7,583 municipalities, which represent approximately $94 \%$ of all Italian municipalities. There were a total of 22,245 elections in the period, and for each electoral round we could separate the first, eligible, from the second, not eligible, term Mayors. Both financial data and data on the electoral rounds are provided by the Ministry of the Interior. Data on the demographic characteristics of each municipality are provided by the National Institute of Statistics (ISTAT).

Figure 1 about here

The time span of our dataset is driven by data availability for the outcomes of interest. Besides the tax rate for both the main residence and the business tax, we were able to recover the deductions for the residence tax (i.e., homestead exemptions), through the Italian Association of Municipalities (IFEL), but only until 2005. ${ }^{13}$ The information on the residence tax deductions is crucial to provide a proxy of the real policy implemented on this tax. As a matter of fact, while on the business property tax, Mayors can only adjust the tax rate, on the residence tax they can either adjust the tax rate, but they still have to comply with a bracket imposed by the central government, or they can increase the deductions for owners. Hence, knowing the total amount of granted deductions provides a proper estimate of the real decision concerning the effective residence tax level. ${ }^{14}$

\footnotetext{
${ }^{12}$ As explained below into the text, we stop in 2005 rather than in 2007 (the residence property tax was abolished in 2008) because we could compute deductions from the residence tax only up to 2005. However, for the period up to 2007 results on the other outcomes of interest are consistent with the results we get on the period 1995-2005. These results were presented in a previous version of this paper and are available from the authors on request.

${ }^{13}$ For a more detailed explanation of our variables see Appendix 2.

${ }^{14} \mathrm{On}$ political grounds, it is also likely to be more advantageous for the Mayor to provide selective differentiate reductions to taxpayers rather than a generalized reduction in the tax rate, as this allows to tailor the benefit more specifically to the advantage of some sectors of the electorate, the ones that are more helpful for his electoral success.
} 
As a second observation, one should also note that although it might appear that the only relevant tax tool for the electoral outcome is the residence property tax, as this is certainly paid by voters, the peculiarities of the Italian institutional framework make the business property tax as much relevant in specific contexts. The reason is that in small size municipalities, the great bulk of the local commercial activity is operated by small firms, owned by residents or residents in a neighborhood municipalities. As a consequence, the policy adopted by Mayors of small centers on the property tax on local productive activity is often at the center of the local public debate. $70 \%$ of Italian municipalities count less than 5,000 inhabitants, so that the electoral relevance of the business property tax in these centers is likely to be decisive. ${ }^{15}$

\section{Empirical analysis}

\subsection{Econometric Identification}

As stressed above, we focus on a specific prediction of the model. Mayors with more reelectoral concerns should be more sensitive to the introduction of a new fiscal tool that is less transparent in terms of political accountability. To proxy the incentives to re-election, we exploit the term limit rule, which has been introduced in Italy with the 1993 electoral reform (Mayors cannot serve more than two terms in a row). Mayors in their first term should then have more incentives to substitute the more transparent tax tool (the property tax) with the less transparent one (the PIT surcharge) since concerns about re-election are more relevant to them than to Mayors who cannot be reelected. We identify the effect of the 1999 reform on Mayors decision using a Difference in Difference (DD) approach. Accordingly, we group municipalities in which the Mayor can be re-elected in the treated set and those where the Mayor cannot be re-elected in the control set. Thus, if a Mayor faces a term limit, his municipality will be included in the control group, whereas the treated group includes municipalities where the Mayor that can be reelected. Other things being equal, we expect that once Mayors are allowed to introduce the PIT surcharge, Mayors in both groups will tend to substitute the property tax with the PIT surcharge, but those facing term limit will substitute less than those eligible.

To offer some descriptive evidence on the different behaviors of the treated and the control facing election, in Figure 2 we plot the average outcomes of interest per year around an election year. ${ }^{16}$ In the figures, the residence tax (a), the business property tax (b), the deductions on the residence tax (c), and the PIT surcharge tax (d) are plotted for those municipalities where the same Mayor served for two full terms. The dashed line represents the tax decisions of Mayors when they were in their first term, and the solid line the tax decisions

\footnotetext{
${ }^{15}$ We should also add that the business property tax is a fertile ground to express political preferences by local politicians, as documented in Bordignon et al. (2013) for larger municipalities, where it is easier to detect the political color of the Mayor.

${ }^{16}$ For instance, 3 years after the election is the year before the next election before 1999 , when the term was 4 years, and it is 2 years before the next election when the term was increased to 5 years in 2000 .
} 
of the same Mayors when they were in their second term. It is apparent from the figure that both types of Mayors behave strategically when the electoral year gets closer, with a drop in the level of property taxes for both types. However, Mayors facing reelection decreases the property taxes more, especially the business property tax. They behave strategically also on the deductions on the residence tax, although it seems that the effect is here concentrated mostly on the year before the election. On the PIT surcharge side, Mayors facing reelections do not decrease the tax as much as Mayors not facing reelections.

Figure 2 about here

To go beyond descriptive evidence, let us then define with $Y_{i t}$ the outcome of interest referred to municipality $i$ at time $t$, and let Eligible be a dummy equal to 1 if there is no term limit and the Mayor can be re-elected and equal to 0 otherwise. Hence, we can identify the effect of the introduction of the new fiscal tool on the residence property tax rate, Residence Tax, the per capita deductions on the residence tax, Deductions, or the business property tax rate, Business Tax, estimating $\delta$, in the following equation:

$$
Y_{i t}=\alpha_{i}+\gamma_{t}+\beta \text { Eligible }_{i t}+\delta \text { Eligible }_{i t} * \text { After } 1999+X_{m t}^{\prime} \tau+\epsilon_{i t}
$$

where $\alpha_{i}$ are municipalities' fixed effects, to take care of time invariant unobserved heterogeneities across municipalities in our sample, and $\gamma_{t}$ are yearly fixed effects to control for exogenous shocks equally affecting both the treated and the control. After 1999 is a dummy equal to 1 for years after 1999 (1999 included), and $\delta$ is the DD estimator. To cope with possible bias due to serial correlation when using repeated cross sections, errors are clustered at the municipal level (Bertrand et al. 2004). $X_{m t}^{\prime}$ includes population density, to control for the urban or rural nature of the municipality, the proportion of residents younger than 14 , and the proportion of residents older than 65 . Since municipal governments are in charge of a wide range of services, including welfare policies, controlling for the composition of the population allows us to control for the different needs of the municipalities. Finally, $X_{m t}^{\prime}$ also includes per capita transfers, both from the central and the regional government, which can also obviously affect the decisions on the local taxation. ${ }^{17}$ Observe that as we estimate equation 8 using a panel fixed effects model, we are controlling for time invariant characteristics of the municipality across our observational period.

We test model 8 on two samples. The first sample includes all municipalities, while the second includes only those municipalities in which the Mayor completed two terms. The latter is our baseline and most robust specification. The reason is that when we use all Mayors we include also those who did not rule a second term and there could be unobservable differences between first and second term Mayors which might lead them to make different tax choices. Restricting the analysis to those who served two terms allow us to detect any different tax choices of the same subject under different re-electoral concerns (Gagliarducci and Nannicini, 2013).

\footnotetext{
${ }^{17}$ Other variables of interest, such as per capita income at the municipality level, are not available for the entire period covered by our analysis.
} 


\subsection{Results}

Table 1 presents the results of model 8 for our outcomes of interest both without and with controls, as shown in Panel $A$ and Panel B. Results are consistent across the two types of sample, all versus only two mandates, and without or with controls. Columns (2), (4), and (6) are our baseline specifications as they refer to municipalities with a Mayor who served two mandates. Concerning the residence property tax rate, Residence Tax decreases, but the effect is not statistically different from zero. However, Deductions on the residence tax increases in a significant way. Hence, it looks like that deductions have been the main tool used to reduce the pressure from the residence property tax on voters. We estimate an increase in Deductions around 11\%, since Deductions is expressed in logs. The introduction of the new tax tool triggered a lower business property tax rate, by 0.08 , which is equal to a $1.4 \%$ decrease at the mean value of the business property tax.

Given that there was a partial freezing of the PIT surcharge in 2003, we provide also the results for the same specifications on the subsample up to 2003. This test also provides a short versus medium run comparison. The results of this check are reported in Table 2 . The results on Business Tax are basically unchanged, with the only difference being in the magnitude of the effect, which results slightly smaller in the 1995-2003 subsample. Results on the residence property tax rate confirm the direction of the effect, with a decrease in the tax rate and an increase in the deductions, but now only the results on the tax rate is statistically robust in the subsample of the mayors serving two terms. This evidence is interestingly matching with the practical devises that can be adopted by the local policy making. It appears that in the short run, the easiest decision was to decrease the tax rate, whereas in the medium run, there was also time to adjust deductions to better tailor the different types of voters.

Tables 1 and 2 about here

\subsection{Robustness Tests}

We test the robustness of our results on three grounds. First, we run checks to detect any anticipatory behaviors in the detected effects and to provide some evidence to support the untestable prediction of a common trend of the treated and the control before the introduction of the PIT surcharge. Second, we control whether switching the panel from the municipal level to the Mayor level, taking into account the time invariant characteristics of the Mayors, could somehow capture some of the effect that we have detected in Table 1. Third, we run equation 8 on the PIT surcharge tax rate (Tax), and on the per capita revenues associated with the PIT (Tax Revenues). Even though before 1999 these variables were equal to zero by definition, we want to check if the PIT surcharge has been effectively used more by Mayors seeking reelection after 1999, so to link the detected effects on the property tax to the alternative fiscal tool employable at the local level.

To test the robustness of our results against anticipatory effects of the policy, in Table

3 we report the results of estimating model 8 using a fake treatment year, $t^{f}$, rather than 
the true treatment year, $t^{*}$. So we set the reform year in 1997 rather than 1999 . Were the coefficient of this placebo test significant, it would mean that even before the introduction of the true treatment the trends of treated and control differ. As apparent from the results in Table 3, the effect of estimating a fake reform in 1997 is not statistically different from zero. This means that we can rule out any anticipatory effect. By the same token, we test the significance of the leads of the reform, which means that we test the significance of the interaction of the years before the reform and the condition of being eligible so to detect any deviation from the common trend assumption. The results in Table 4 show that the leads of the reform are not statistically different from zero, so that we can reasonable argue that the main assumption for a correct identification is plausible in our case.

Tables 3 and 4 about here

As a second check, we control if estimating model 8 using a panel fixed effects at the Mayor level change dramatically our results. The purpose of this check is to remove all the time invariant characteristics of a Mayor, as his innate levels of skill, which could effect our results. Table 5 shows the results for the subsamples of the Mayors who served two mandates so to focus on our most robust specifications. Compared to the results shown in Table 1, the effect on the Business Tax and Deductions still hold with a slight decrease in the magnitude of the effect, while the result on Residence Tax gains statistical significance. These results do not undermine the validity of our preferred specification, which remains the one controlling for the fixed effect at the municipal level, since fixed effects at the municipal level better capture structural characteristics and conditions that any type of Mayor needs to cope with when governing a given municipality.

Table 5 about here

Finally, in Table 6 we provide evidence on the level of the PIT surcharge and its revenues (in $\log$ ) for the different samples and type of included fixed effects. As apparent from the results, the PIT surcharge has been exploited at the local level, particularly by Mayors who could be re-elected, that increased the PIT surcharge on average about $20 \%$ more than the Mayors who could not be re-elected. ${ }^{18}$

Table 6 about here

\footnotetext{
${ }^{18}$ As a further robustness text for our theory, notice that taking our model literally, we should expect for first term Mayors an increase in tax revenues after the reform, as this increase is exactly what allows the bad government to reduce effort in the partial pooling strategy equilibrium, so making pooling behavior easier. We did check for it, by testing Model (8) using as outcome the total revenues from the PIT surcharge and the property tax (i.e., summing together the revenues for business and main residence taxation). We indeed found a positive and significant effect of being eligible after 1999 equal to 11.27 euro, which accounts for an increase equal to $8 \%$ at the mean of the total revenues from PIT and property tax (136 euro).
} 


\subsection{Where the effect matters the most}

To corroborate our findings, in this section we investigate if there has been any heterogeneous response to the 1999 reform across municipalities with different characteristics. Here we only focus on the business property tax as the outcome of interest, because this is easier to interpret given that the effect can only pass through the tax rate, and not through the combined effect of adjusting both the tax rate in the short run and the deductions in the medium run as for the residence tax, as discussed in the previous analysis.

We consider three groups of municipal characteristics that might affect the response to the 1999 reform. A first group of indicators proxy levels of social capital and of information on local policy. The measures of social capital represent an interesting check for our analysis; social capital is known to improve political accountability (Nannicini et al. 2013). The expectation is therefore that in municipalities with higher level of social capital, voters should be more informed about increases in the PIT surcharge, and the ability of the Mayor to conceal fiscal policy should decrease accordingly. This channel is approximated with two variables which capture whether the municipality is located in a Southern region, where the level of social capital is known to be generally lower (Nannicini et al. 2013), and the number of no profit organizations operating in the area, a commonly used proxy for social capital (Guiso et al. 2008). We also control for the number of daily non-sport newspapers circulating in the area as a measure of the available information on the activities of local politicians.

Dealing with the municipal characteristics, we use the municipality size, exploiting the threshold of 5,000 inhabitants. Municipalities below 5,000 inhabitants are small, and according to our previous argument, we should detect a stronger effect on the business property tax in those centers. Moreover, municipalities below 5,000 inhabitants have been exempted by the Domestic Stability Pact (DSP), introduced for all municipalities in 1999, starting from 2001. As a consequence, these municipalities are less monitored by the national government, which could also allow for more game play on the local tax system (Grembi et al., 2014). Finally, we also exploit the location of a municipality, that is, whether it belongs to a region with special statute $(R S S)$ or to a region with ordinary statute $(R S O)$. The 5 Italian $R S S$ have larger amount of resources and their municipalities generally face less financial constraints as compared to those located in $R S O{ }^{19}$ Since $R S S$ municipalities have more resources to start with, they will have less need to adjust the local taxation scheme, since they can rely more heavily on other sources of revenues (i.e., transfers). Hence, the incentive to substitute between tax types for the $R S S$ municipalities should be lower.

To analyze these issues, we generate dummies, $D$, for each characteristic discussed above and interact them with Eligible $_{i t} *$ After 1999 using our DD approach to estimate the model. For each channel, we report the results for $\delta$ in each subsample defined on $D$ and the significance of the difference between the two samples. The latter is captured by the parameter $\lambda$, as specified in the following model:

$Y_{i t}=\alpha_{i}+\gamma_{t}+\beta$ Eligible $_{i t}+\delta$ Eligible $_{i t} *$ After $1999+\lambda D *$ Eligible $_{i t} *$ After $_{1999}+X_{m t}^{\prime} \tau+\epsilon_{i t}$

\footnotetext{
${ }^{19}$ The RSS regions are Sicilia, Sardegna, Valle d'Aosta, Friuli Venezia Giulia, and Trentino Alto Adige.
} 
Where $D$ is the dummy for each channel. For instance, for the heterogeneity of North vs. South, $D=1$ if a municipality is located in the South and similarly for the other channels. ${ }^{20}$ Notice that as we are estimating a panel fixed effect at the municipality level, when $D$ is not time variant, as in the case of geographical location, we do not need to control for it in the model. The results of this analysis, estimated on the subsample of the Mayors serving two terms, are reported in Table 7 .

Table 7 about here

The social capital channel fully confirms our expectations: lower level of social capital approximated through different measures and lower level of press coverage are associated with a stronger decrease of the property tax after the 1999 reform, as shown in columns (1)-(3). As apparent from column (4), the effect on the business property tax is stronger and significant only in small municipalities; it is also stronger in municipalities located in ordinary statutes regions compared with special statute regions (column (5)), again confirming expectations.

\section{Conclusions}

In this paper, we propose a model that predicts that local politicians facing electoral incentives tend to substitute more transparent fiscal tools with less transparent ones, and with that reducing political accountability. An empirical analysis on Italian municipalities confirms these hypotheses; there is strong evidence that Mayors that could be re-elected used more the (less transparent) income tax surcharge to reduce the (more transparent) property tax. Interestingly, and in line with the political economy explanation suggested in this paper, it also turns out that at least in the medium run Mayors used selective deductions for reducing the pressure of the property tax on residence owners, rather than across the board reductions in the tax rate. While our explanation on the lower level of transparency of the income tax is based on the overlapping of governments in the decisions concerning its tax rate, it must be acknowledged that an alternative explanation is just that, for some reasons, the property tax is more "salient" for voters than the income tax, leading politicians with electoral incentives to act differently on these two fiscal tools. While we cannot reject this alternative explanation, we notice that some of our results, such as the fact that the effects were stronger in municipalities characterized by a lower level of social capital and a lower diffusion of the local press, seem to point more in favor of our explanation than a simple salience story. It would be difficult to explain why in municipalities with lower level of social capital the property tax is also more salient than in others.

Our results have important implications for the literature on fiscal federalism. In order to save administrative costs, many countries use surcharges on national taxes as a source of revenue for local governments (Shah, 2006), and while there is already a large literature pointing out the inefficiencies that this overlapping of governments on the same tax base might cause (e.g. Keen, 1998), the political effects in terms of a reduction of accountability

\footnotetext{
${ }^{20}$ See Appendix 2 for a detailed explanation of the variables.
} 
of local governments has been less discussed in the literature ${ }^{21}$. Our results at least suggest that the issue deserves to be taken seriously. In particular, on normative grounds, our analysis would imply that in the choice of local tax tools, preeminence should be given to local taxes that could be unambiguously attributed to local governments. Further theoretical and empirical analysis on these topics would be useful in providing a better understanding of these important policy issues.

\footnotetext{
${ }^{21}$ It might be that in some countries, such as the European Nordic countries, where the role of the local income tax is much more important than in the Italian case and where there are no other important sources of tax revenues, voters are more conscious of the existence of a local tax on income and keep local politicians accountable for their choices on this tax too. Still, even in these countries the issue of the overlapping of governments, national and local, on the same tax base, labor income, remains problematic (e.g. Norrengard, 1997).
} 


\section{References}

[1] Alt J.E., Lassen D.D., 2003. "Fiscal Transparency and Fiscal Policy Outcomes in OECD Countries", EPRU Working Paper Series, Economic Policy Research Unit (EPRU), University of Copenhagen.

[2] Ambrosanio M.F., Bordignon M., 2006, "Normative versus Positive Theories of Revenue Assignments in Federations" in Ahmad and Brosio ed., Handbook of Fiscal Federalism, Edward Elgar.

[3] Cartocci, R., 2007. Mappe del Tesoro. Bologna: il Mulino.

[4] Bertrand M., Duflo E., Mullainathan S. 2004 , "How Much Should we Trust Differencesin-Differences Estimates?", The Quarterly Journal of Economics Vol. 119 (1), 249-275.

[5] Besley T., 2007, "Principled Agents?. The Political Economy of Good Government", Oxford University Press.

[6] Besley T., Case A. 1995, "Incumbent Behavior: Vote-Seeking, Tax-Setting, and Yardstick Competition" The American Economic Review, Vol. 85, No. 1 (Mar.), pp. 25-45.

[7] Boadway R., 2006 "Intergovernmental Redistributive Transfers: Efficiency and Equity", in Ahmad and Brosio ed., Handbook of Fiscal Federalism, Edward Elgar.

[8] Boadway R., Marchand M., and Vigneault M., 1998, "The consequences of overlapping tax bases for redistribution and public spending in a federation." Journal of Public Economics, Vol. 68, 453-478.

[9] Bordignon M., Minelli E. 2001, "Rules Transparency and Political Accountability." Journal of Public Economics, Vol. 80, pp. 73-98.

[10] Bordignon M., Cerniglia, F. Revelli, F., 2003, "In search of yardstick competition: a spatial analysis of Italian municipality property tax setting," Journal of Urban Economics, Vol. 54, pp. 199-217.

[11] Bordignon M., Nannicini, T. Tabellini, G., 2014, "Moderating Political Extremism: Single Round vs Runoff Elections under Plurality Rule, " CEPR Discussion Papers 10323, C.E.P.R. Discussion Papers.

[12] Bordignon M., Gamalerio, M. Turati G., 2015. "Decentralization, Vertical Fiscal Imbalance and Political Selection", mimeo, Catholic University of Milan.

[13] Bracco, E., Porcelli F., Redoano, M., 2013, "Political Competition, Tax Salience and Accountability: Theory and Some Evidence from Italy", Working Paper, CESifo Working Paper Series 4167.

[14] Cabral, M., C. Hoxby, 2012, "The Hated Property Tax: Salience, Tax Rates, and Tax Revolts," NBER Working Paper 18514. 
[15] Censis 2011, Il Rapporto tra gli italiani e il fisco, Roma.

[16] Coate S., Morris S. 1995, "On the form of transfers to special interests" Journal of Political Economy, Vol. 103, pp. 1210-1235.

[17] Devarajan S., Khemani S., and Shah S. 2007, "The Politics of Partial Decentralization", Washington, The World Bank.

[18] Gagliarducci S., Nannicini T. 2013, "Do Better Paid Politicians Perform Better? Disentangling Incentives from Selection", Journal of the European Economic Association, vol.11(2), 369-398.

[19] Grembi V., Nannicini T., Troiano, U. 2015, "Do Fiscal Rules Matter?", American Economic Journal: Applied Economics, Forthcoming.

[20] Guiso, L., Sapienza, P. and L. Zingales. 2008, "Long Term Persistence." Unpublished.

[21] Keen M. 1998, "Externalities in the Theory of Fiscal Federalism" IMF Staff Working Paper, Vol.45.

[22] Klien M., 2014, "Tariff increases over the electoral cycle: A question of size and salience," European Journal of Political Economy, Vol. 36, pp.228-242.

[23] Lockwood B., 2006, "Fiscal Decentralization: a Political Economy Perspective," Warwick Economic R. P. No. 721.

[24] Milesi-Ferretti G.M., 2000, "Good,Bad or Ugly? On The effects of Fiscal Rules with Creative Accounting," IMF staff WP, No. 172.

[25] Nannicini, T., Stella A., Tabellini, G., and U. Troiano, 2013, "Social Capital and Political Accountability," American Economic Journal: Economic Policy, 5 , 222-250.

[26] Norregaard, J., 1997, "Tax Assignment" in T. Ter-Minassian (ed.) Fiscal Federalism in Theory and Practise, International Monetary Fund, Washington.

[27] Norregaard, J., 2013, "Taxing Immovable Property Revenue Potential and Implementation Challenges," IMF Working Papers WP 129.

[28] Shah, A., 2006, "Local Governance in Industrial Countries," World Bank.

[29] Rogoff K., Sibert A. 1988, "Elections and Macroeconomic Policy Cycles," Review of Economic Studies, LV, pp. 1-16. 


\section{Tables and Figures}

Figure 1: Property and Pit Tax introduction

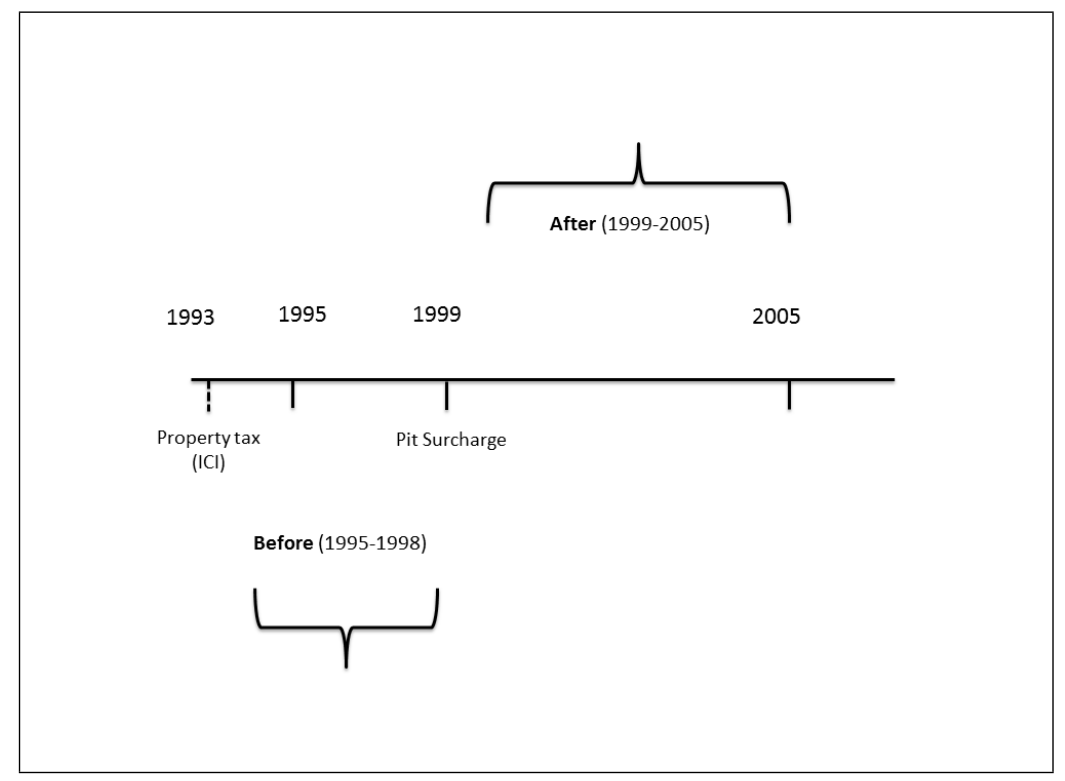

Notes: This is the time line of our observational period. We stop in 2005, because data on the residence property tax deductions are not available after 2005 . 


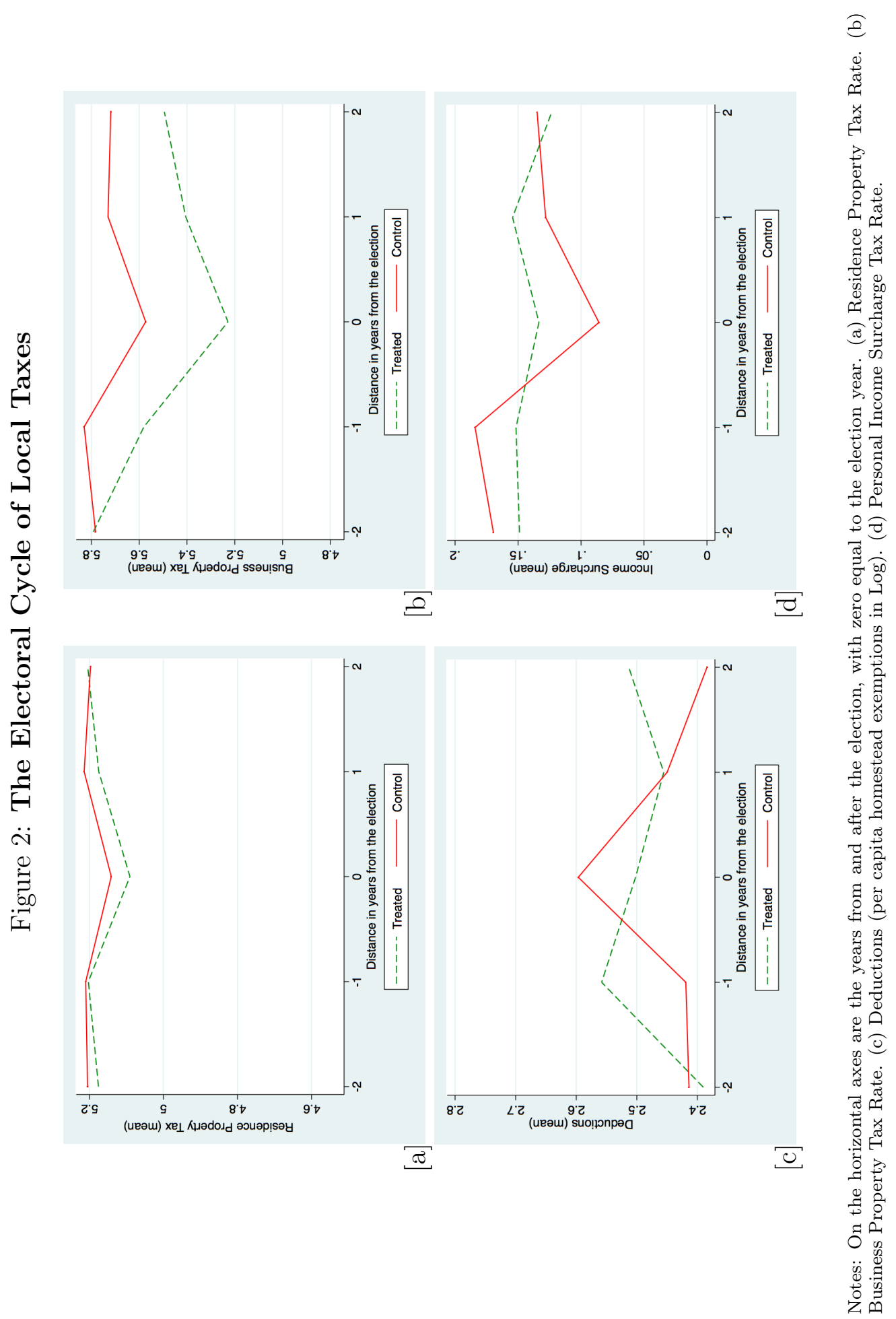




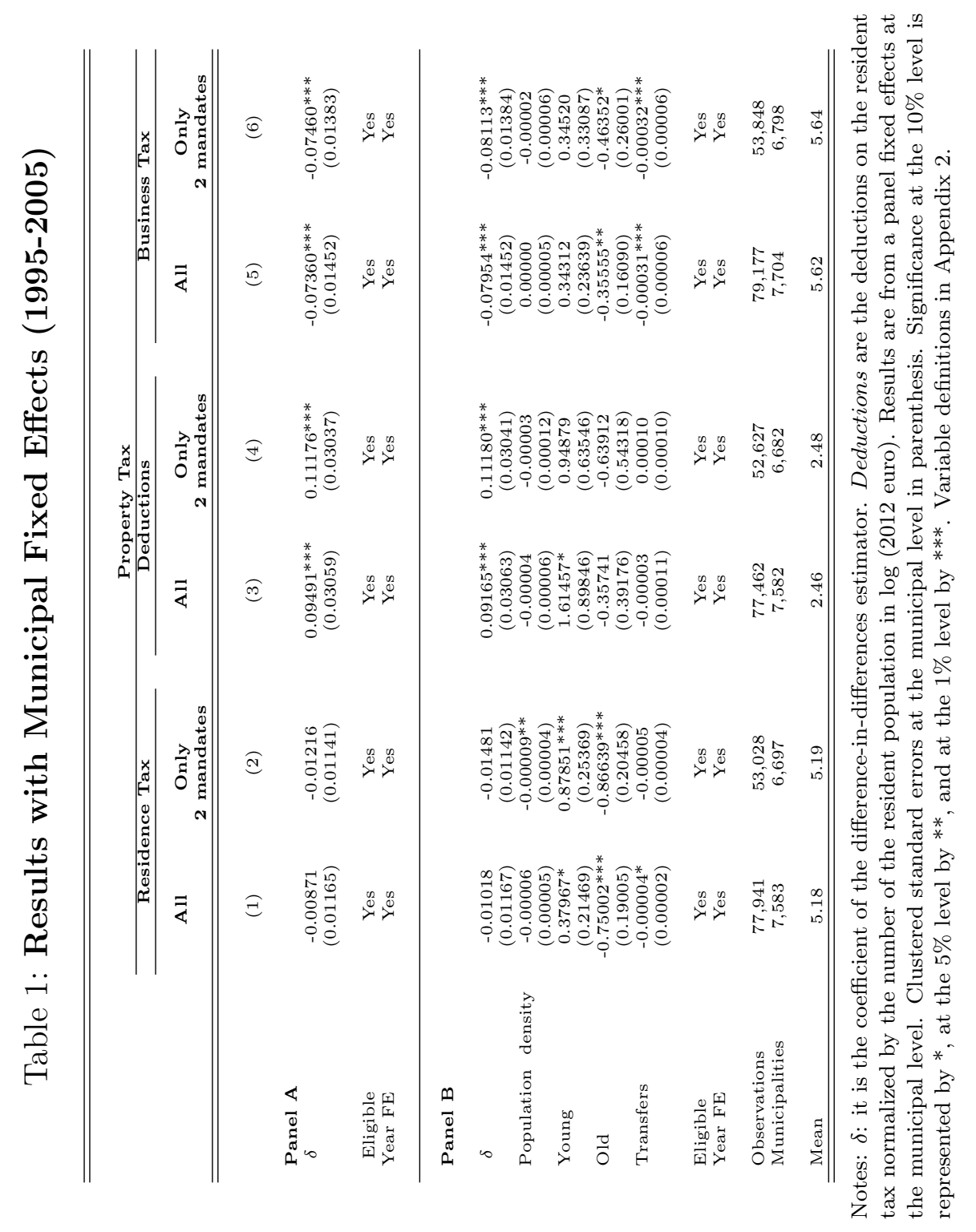




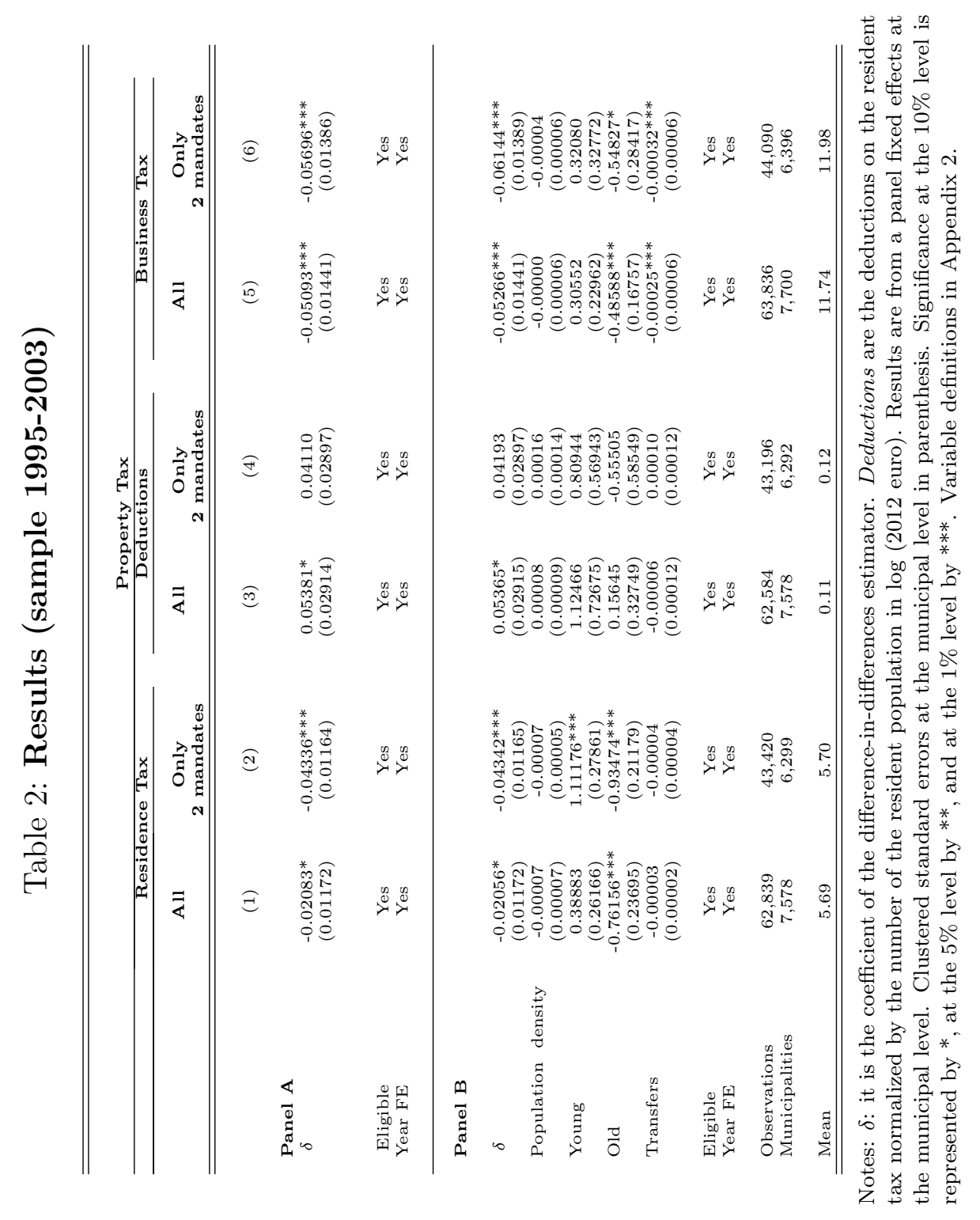


Table 3: Placebo Test: Results with PIT in 1997

\begin{tabular}{|c|c|c|c|c|}
\hline & \multicolumn{2}{|c|}{ All } & \multicolumn{2}{|c|}{ Only 2 mandates } \\
\hline & (1) & $(2)$ & $(3)$ & $(4)$ \\
\hline \multicolumn{5}{|c|}{ Panel A: Residence Tax } \\
\hline$\delta$ & $\begin{array}{c}0.00669 \\
(0.06873)\end{array}$ & $\begin{array}{c}0.00462 \\
(0.06876)\end{array}$ & $\begin{array}{c}0.01054 \\
(0.07238)\end{array}$ & $\begin{array}{c}0.00406 \\
(0.07237)\end{array}$ \\
\hline Eligible & Yes & Yes & Yes & Yes \\
\hline Year FE & Yes & Yes & Yes & Yes \\
\hline Controls & No & Yes & No & Yes \\
\hline Observations & 77,941 & 77,941 & 53,028 & 53,028 \\
\hline Municipalities & 7,583 & 7,583 & 6,697 & 6,697 \\
\hline \multicolumn{5}{|c|}{ Panel B: Deductions } \\
\hline$\delta$ & $\begin{array}{c}0.00765 \\
(0.14931)\end{array}$ & $\begin{array}{c}0.00258 \\
(0.14896)\end{array}$ & $\begin{array}{c}0.04390 \\
(0.15663)\end{array}$ & $\begin{array}{c}0.04326 \\
(0.15604)\end{array}$ \\
\hline Eligible & Yes & Yes & Yes & Yes \\
\hline Year FE & Yes & Yes & Yes & Yes \\
\hline Controls & No & Yes & No & Yes \\
\hline Observations & 77,459 & 77,459 & 52,625 & 52,625 \\
\hline Municipalities & 7,582 & 7,582 & 6,682 & 6,682 \\
\hline \multicolumn{5}{|c|}{ Panel C: Business Property Tax } \\
\hline$\delta$ & $\begin{array}{l}-0.03316 \\
(0.07664)\end{array}$ & $\begin{array}{l}-0.04540 \\
(0.07605)\end{array}$ & $\begin{array}{c}0.00722 \\
(0.07007)\end{array}$ & $\begin{array}{c}-0.00691 \\
(0.06914)\end{array}$ \\
\hline Eligible & Yes & Yes & Yes & Yes \\
\hline Year FE & Yes & Yes & Yes & Yes \\
\hline Controls & No & Yes & No & Yes \\
\hline Observations & 79,177 & 79,177 & 53,848 & 53,848 \\
\hline Municipalities & 7,704 & 7,704 & 6,798 & 6,798 \\
\hline
\end{tabular}

Notes: $\delta$ : it is the coefficient of the difference-in-differences estimator once the reform here is set at 1997 . Results are from a panel fixed effects at the municipal level. Clustered standard errors at the municipal level in parenthesis. Controls include: Population density, Young, Old, Transfers. Significance at the $10 \%$ level is represented by $*$, at the $5 \%$ level by $* *$, and at the $1 \%$ level by $* * *$. Variable definitions in Appendix 2. 


\section{Table 4: Testing the Common Trend: Leads Results}

\begin{tabular}{|c|c|c|}
\hline & \multicolumn{2}{|c|}{ Only 2 mandates } \\
\hline & (1) & (2) \\
\hline \multicolumn{3}{|c|}{ Panel A: Residence Tax } \\
\hline$\delta$ at $t-3$ & $\begin{array}{c}0.00880 \\
(0.06671)\end{array}$ & $\begin{array}{c}0.00832 \\
(0.06673)\end{array}$ \\
\hline$\delta$ at $t-2$ & $\begin{array}{c}0.02603 \\
(0.09562)\end{array}$ & $\begin{array}{c}0.02225 \\
(0.09590)\end{array}$ \\
\hline$\delta$ at $t-1$ & $\begin{array}{c}0.02659 \\
(0.09579)\end{array}$ & $\begin{array}{c}0.02159 \\
(0.09603)\end{array}$ \\
\hline Eligible & Yes & Yes \\
\hline Year FE & Yes & Yes \\
\hline Controls & No & Yes \\
\hline Observations & 53,028 & 53,028 \\
\hline Municipalities & 6,697 & 6,697 \\
\hline \multicolumn{3}{|c|}{ Panel B: Deductions } \\
\hline$\delta$ at $t-3$ & $\begin{array}{c}0.03480 \\
(0.10387)\end{array}$ & $\begin{array}{c}0.03681 \\
(0.10328)\end{array}$ \\
\hline$\delta$ at $t-2$ & $\begin{array}{l}-0.06579 \\
(0.19060)\end{array}$ & $\begin{array}{c}-0.06326 \\
(0.18995)\end{array}$ \\
\hline$\delta$ at $t-1$ & $\begin{array}{c}0.00753 \\
(0.19227)\end{array}$ & $\begin{array}{c}0.00756 \\
(0.19159)\end{array}$ \\
\hline Eligible & Yes & Yes \\
\hline Year FE & Yes & Yes \\
\hline Controls & No & Yes \\
\hline Observations & 52,625 & 52,625 \\
\hline Municipalities & 6,682 & 6,682 \\
\hline \multicolumn{3}{|c|}{ Panel C: Business Tax } \\
\hline$\delta$ at $t-3$ & $\begin{array}{c}0.00742 \\
(0.08388)\end{array}$ & $\begin{array}{c}0.00158 \\
(0.08311)\end{array}$ \\
\hline$\delta$ at $t-2$ & $\begin{array}{c}0.10009 \\
(0.10163)\end{array}$ & $\begin{array}{c}0.08696 \\
(0.09994)\end{array}$ \\
\hline$\delta$ at $t-1$ & $\begin{array}{c}0.05231 \\
(0.10119)\end{array}$ & $\begin{array}{c}0.04044 \\
(0.09951)\end{array}$ \\
\hline Eligible & Yes & Yes \\
\hline Year FE & Yes & Yes \\
\hline Controls & No & Yes \\
\hline Observations & 53,848 & 53,848 \\
\hline Municipalities & 6,798 & 6,798 \\
\hline
\end{tabular}

Notes: $\delta$ : it is the coefficient of the difference-in-differences estimator once the reform here is set at 1997. Results are from a panel fixed effects at the municipal level. Clustered standard errors at the municipal level in parenthesis. Controls include: Population density, Young, Old, Transfers.Significance at the $10 \%$ level is represented by *, at the $5 \%$ level by ${ }^{* *}$, and at the $1 \%$ level by $* * *$. Variable definitions in Appendix 2 . 


\section{Table 5: Results with Mayor Fixed Effects (Only two mandates)}

\begin{tabular}{|c|c|c|c|}
\hline & \multicolumn{3}{|c|}{ Property Tax } \\
\hline & Residence Tax & Deductions & Business Tax \\
\hline & 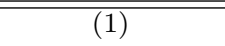 & 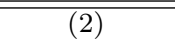 & $\overline{(3)}$ \\
\hline$\underset{\delta}{\text { Panel A }}$ & $\begin{array}{c}-0.02307^{* *} \\
(0.01125)\end{array}$ & $\begin{array}{c}0.06867^{* *} \\
(0.03022)\end{array}$ & $\begin{array}{c}-0.04158^{* * *} \\
(0.01385)\end{array}$ \\
\hline $\begin{array}{l}\text { Eligible } \\
\text { Year FE }\end{array}$ & $\begin{array}{l}\text { Yes } \\
\text { Yes }\end{array}$ & $\begin{array}{l}\text { Yes } \\
\text { Yes }\end{array}$ & $\begin{array}{l}\text { Yes } \\
\text { Yes }\end{array}$ \\
\hline \multicolumn{4}{|l|}{ Panel B } \\
\hline$\delta$ & $\begin{array}{c}-0.02223^{* *} \\
(0.01126)\end{array}$ & $\begin{array}{c}0.06962^{* *} \\
(0.03020)\end{array}$ & $\begin{array}{c}-0.04122^{* * * *} \\
(0.01383)\end{array}$ \\
\hline Population density & $\begin{array}{l}-0.00005 \\
(0.00003)\end{array}$ & $\begin{array}{c}0.00003 \\
(0.00010)\end{array}$ & $\begin{array}{l}-0.00002 \\
(0.00005)\end{array}$ \\
\hline Young & $\begin{array}{c}0.91781^{* * *} \\
(0.24735)\end{array}$ & $\begin{array}{c}0.80689 \\
(0.53364)\end{array}$ & $\begin{array}{c}0.26689 \\
(0.28006)\end{array}$ \\
\hline Old & $\begin{array}{c}-0.75151^{* * *} \\
(0.19294)\end{array}$ & $\begin{array}{l}-0.82016 \\
(0.54311)\end{array}$ & $\begin{array}{l}-0.48105^{*} \\
(0.26567)\end{array}$ \\
\hline Transfers & $\begin{array}{l}-0.00005 \\
(0.00003)\end{array}$ & $\begin{array}{c}0.00008 \\
(0.00010)\end{array}$ & $\begin{array}{c}-0.00029^{* * *} \\
(0.00006)\end{array}$ \\
\hline Eligible & Yes & Yes & Yes \\
\hline Year FE & Yes & Yes & Yes \\
\hline Observations & 53,028 & 52,627 & 53,848 \\
\hline Mayors & 8,711 & 8,685 & 8,839 \\
\hline Mean & 5.19 & 2.48 & 5.64 \\
\hline
\end{tabular}

Notes: $\delta$ : it is the coefficient of the difference-in-differences estimator. Deductions are the deductions on the resident tax normalized by the number of the resident population in $\log (2012$ euro). Results are from a panel fixed effects at the mayor level for the period 1995-2005. Clustered standard errors at the municipal level in parenthesis. Significance at the $10 \%$ level is represented by *, at the $5 \%$ level by **, and at the $1 \%$ level by $* * *$. Variable definitions in Appendix 2. 


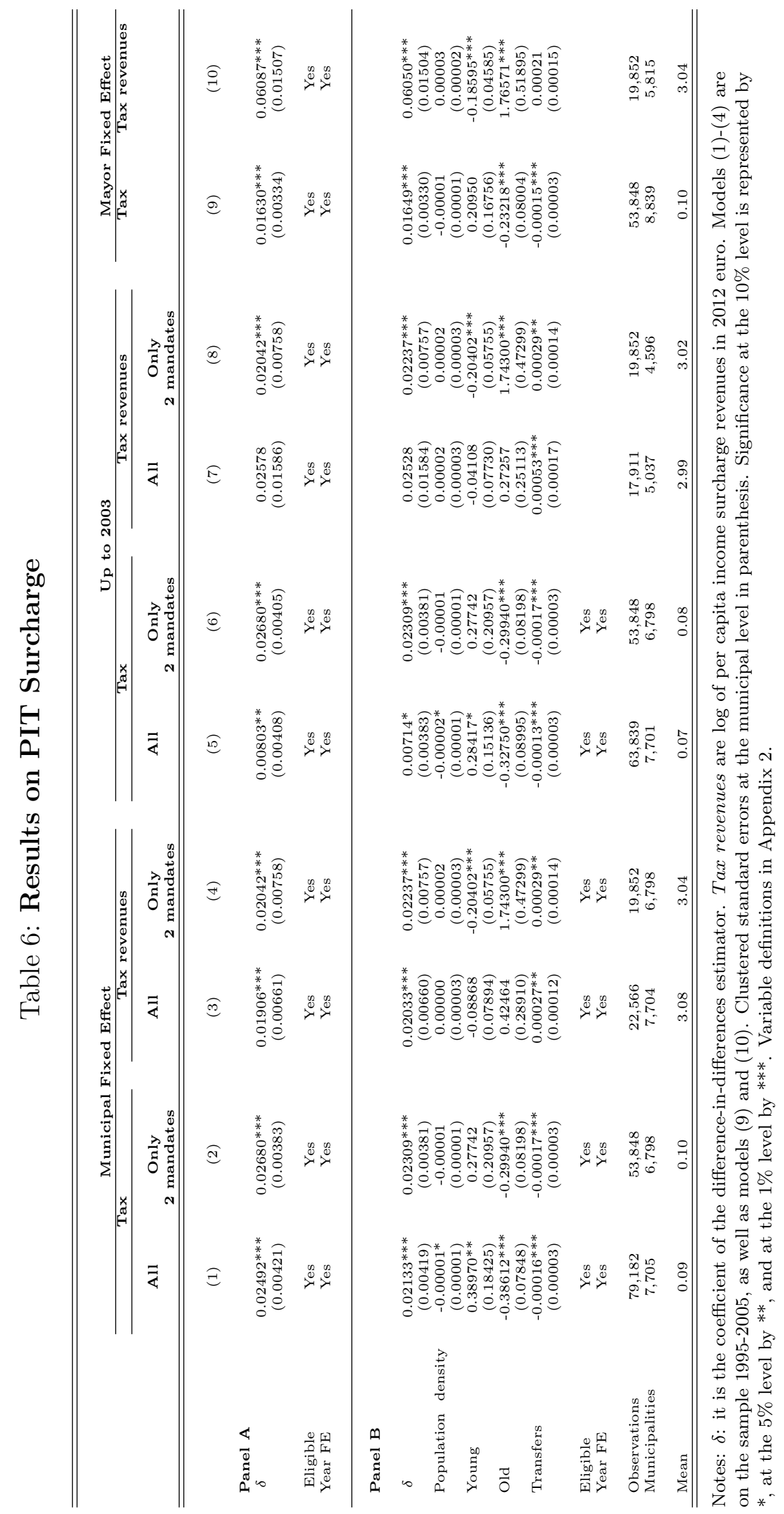




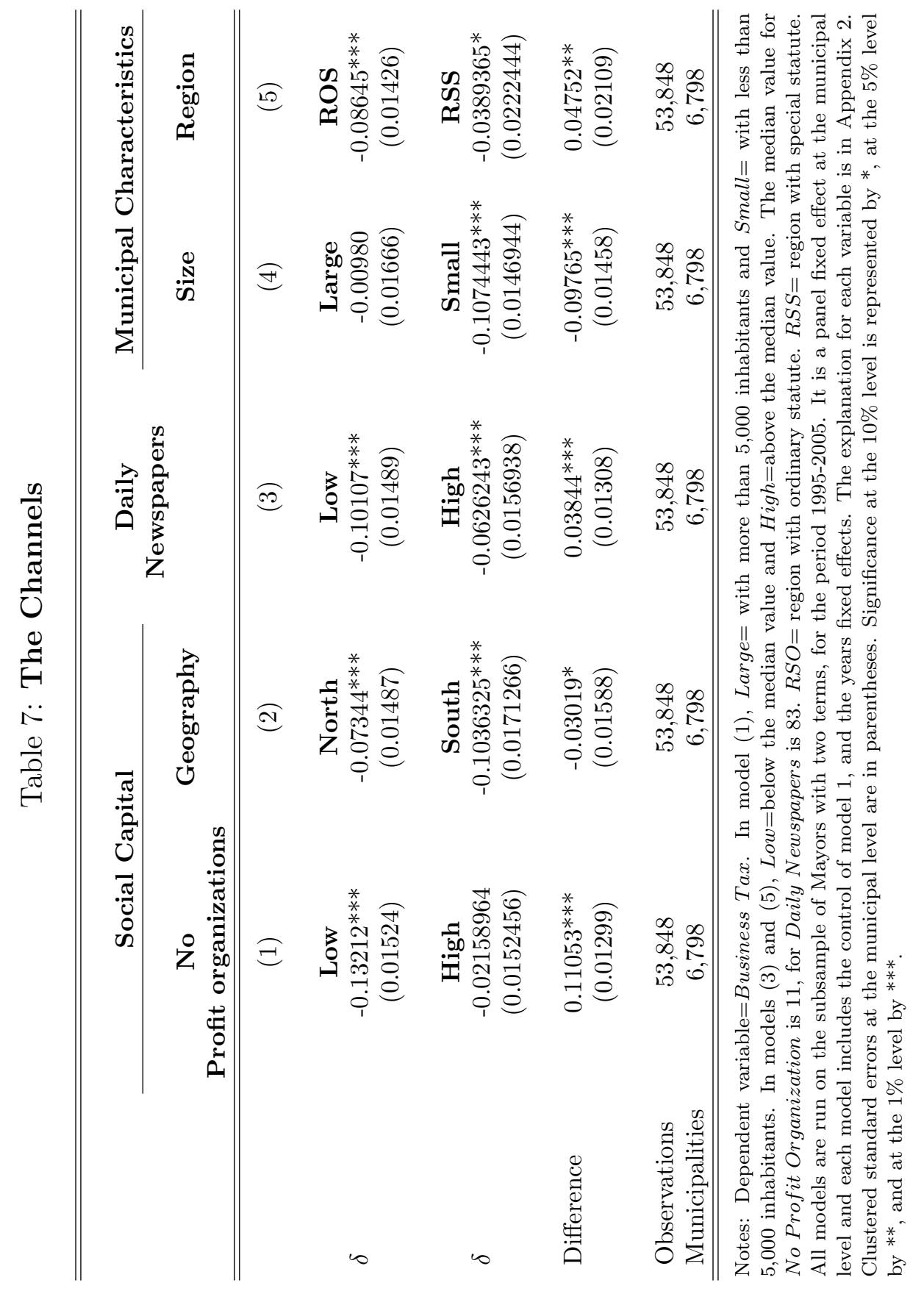




\section{Online Appendix 1}

\section{Proof of proposition 1.}

By playing the mimicking strategy, the incompetent Mayor suffers a loss in the first period:

$$
-\Delta w_{1}=u\left(\tau^{*}(\underline{s})\right)-\frac{\bar{s}}{2}\left(e^{*}(\underline{s})^{2}\right)-\left(u\left(\tau^{*}(\bar{s})\right)-\frac{\bar{s}}{2}\left(e^{*}(\bar{s})\right)^{2}\right)<0
$$

This loss must be compared to the potential advantage in terms of the probability of being re-elected. Let $n_{1}$ be the probability of re-election that the incompetent government expects by playing the mimicking strategy (if the incumbent is not re-elected, his utility is normalized to zero in the second period). The incompetent Mayor would then play the mimicking strategy if

$$
-\Delta w_{1}+n_{1} \delta\left(u\left(\tau^{*}(\bar{s})\right)-\frac{\bar{s}}{2}\left(e^{*}(\bar{s})\right)^{2}+E\right) \geq 0
$$

or if

$$
n_{1} \delta \geq \frac{\Delta w_{1}}{\left(u\left(\tau^{*}(\bar{s})\right)-\frac{\bar{s}}{2}\left(e^{*}(\bar{s})\right)^{2}+E\right)} \equiv k_{1}
$$

where $\delta \in(0,1)$ is the discount factor. Notice that $0<k_{1}<1$ and that $k_{1}$ is strictly increasing in the difference between $(\bar{s}-\underline{s})$ and strictly decreasing in the exogenous utility for holding office, $E$. To see if this strategy pays for the incompetent Mayor, we have to compute the equilibrium election probability $n_{1}$. At the equilibrium, the rational voter would expect the incompetent incumbent Mayor to play the mimicking strategy. But as she observes the same choices by both types of government in all cases, her ex post beliefs, having observed $\tau^{*}(\underline{s})$, can only coincide with her ex ante beliefs, $q$. Hence, the voter is indifferent in the choice of re-electing the incumbent or electing the opposing candidate. To rule out mixed strategy equilibria, let us assume that when indifferent, the voter votes for the incumbent, implying $n_{1}=1$. We can then conclude that the incompetent Mayor will play the mimicking strategy in the first period whenever $\delta \geq k_{1}$. We call an equilibrium where the incompetent Mayor in the first period just does what the competent one would do in the same case, a fully pooling equilibrium.

On the other hand, if $\delta<k_{1}$, it is easy to check that the fully pooling equilibrium cannot be sustained, while a separating equilibrium, in which each type of Mayor plays his favorite strategy in the first period, can be sustained. At a separating equilibrium, the rational voter would assign probability 1 that the government playing $\tau^{*}(\underline{s}), e^{*}(\underline{s})$ is a competent one and would then re-elect him for sure (as $1>q$ ) in the ensuing elections. Yet as $\delta<k_{1}$, it is not convenient for the incompetent Mayor to deviate to $\tau^{*}(\underline{s}), e^{*}(\underline{s})$ from the separating equilibrium. Whatever the beliefs of the voters upon observing this deviation, the Mayor is better off by sticking to his preferred strategy $\tau^{*}(\bar{s}), e^{*}(\bar{s})$ and losing the election. This implies 
that the separating equilibrium is an equilibrium for our game when $\delta<k_{1}$. By the same token, the separating equilibrium cannot be an equilibrium for $\delta \geq k_{1}$, as the incompetent Mayor would then have a profitable deviation (e.g. playing $\tau^{*}(\underline{s}), e^{*}(\underline{s})$ and being re-elected for sure) which would destroy this equilibrium. Collecting these observations, we obtain proposition 1. QED

A surcharge tax on the personal income tax.

We first derive some of the properties discussed into the text, then we prove Proposition 2. To solve the model, and find the Bayesian equilibria when the Mayor can also impose the PIT surcharge, we again work backwards. In the second period, as there are no electoral incentives, a Mayor of type $s$, when faced with a central government income tax rate $T$, would then choose $(t, e, \tau)$ by solving the following problem:

$$
\operatorname{Max} U(H(\tau))-p H(\tau)+(1-(T+t)) L(T+t)+V(1-L(T+t))+E-\frac{s}{2} e^{2}
$$

subject to:

$$
1=\tau H(\tau)+t L(T+t)+e
$$

where $p=(1-(1-\tau) r)$. The solutions implicitly determine the optimal choices of government as a function of the two parameters of the problem, $s$ and $T ; \tau^{*}(s, T), t^{*}(s, T), e^{*}(s, T)$. To sign the effects, we compute the FOC for the previous problem and differentiate them. We first prove, as indicated in the text, that $\partial \tau^{*}(s, T) / \partial s>0, \partial t^{*}(s, T) / \partial s>0, \partial e^{*}(s, T) / \partial s<0$.

Proof: Changes in s Solving the budget constraint for $e$ and substituting in the government's problem, this can be rewritten as

$\operatorname{Max}_{\tau, t} F=U(H(\tau))-p H(\tau)+(1-(T+t)) L(T+t)+V(1-L(T+t))+E-\frac{s}{2}(1-$ $\tau H(\tau)-t L(T+t))^{2}$

Invoking the envelope theorem, the FOC for this problem can be written as:

$F_{\tau}=-r H(\tau)+s(1-\tau H(\tau)+t L(T+t))\left(H(\tau)+\tau H^{\prime}(\tau)\right)=0$

$F_{t}=-t L(T+t)+s(1-\tau H(\tau)+t L(T+t))\left(L(T+t)-t L^{\prime}(T+t)=0\right.$

Differentiating totally the FOC, we get:

$F_{\tau \tau} d \tau+F_{\tau t} d t+F_{\tau s} d s=0$

$F_{t \tau} d \tau+F_{t t} d t+F_{t s} d s=0$

forming the matrix and inverting we get: 


$$
\begin{aligned}
& \frac{d \tau}{d s}=-\frac{1}{\Delta}\left(F_{t t} F_{\tau s}-F_{\tau t} F_{t s}\right) \\
& \frac{d t}{d s}=-\frac{1}{\Delta}\left(F_{\tau \tau} F_{t s}-F_{\tau t} F_{\tau s}\right)
\end{aligned}
$$

where $\Delta=F_{\tau \tau} F_{t t}-\left(F_{t \tau}\right)^{2}>0$

$F_{\tau s}=e^{*} H\left(1-\varepsilon^{h}\left(\tau^{*}\right)\right)>0$

$F_{t s}=e^{*} L\left(1-\frac{t^{*}}{\theta} \varepsilon^{l}(\theta)\right)>0$

but the FOC implies $r\left(1-\frac{t^{*}}{\theta} \varepsilon^{l}(\theta)\right)=1-\varepsilon^{h}\left(\tau^{*}\right)$. Dividing through $F_{\tau s} / F_{t s}=r H / L$

hence $\operatorname{sign} \frac{d \tau}{d s}=-\operatorname{sign}\left(F_{t t} \frac{r H}{L}-F_{\tau t}\right)$ and $\operatorname{sign} \frac{d t}{d s}=-\operatorname{sign}\left(F_{\tau \tau}-F_{\tau t} \frac{r H}{L}\right)$

$F_{\tau \tau}-F_{\tau t} \frac{r H}{L}=H\left(\tau^{*}\right)\left(\left(-s H\left(\tau^{*}\right)\right)\left(1-\varepsilon^{h}\left(\tau^{*}\right)\right)^{2}-s e^{*} \varepsilon_{\tau}^{h}\left(\tau^{*}\right)\right)+s(H(\tau))^{2}\left(1-\varepsilon^{h}\left(\tau^{*}\right)\right)^{2}=$ $-s e^{*} H\left(\tau^{*}\right) \varepsilon_{\tau}^{h}\left(\tau^{*}\right)$.

Hence $\varepsilon_{\tau}^{h}\left(\tau^{*}\right)>0$ implies $\frac{d t}{d s}>0$.

$$
\begin{aligned}
& F_{t t} \frac{r H}{L}-F_{t \tau}=-s r L H\left(1-\frac{t^{*}}{\theta} \varepsilon^{l}(\theta)\right)^{2}-\frac{s e^{*}}{\theta^{2}} r H\left(T \varepsilon^{l}(\theta)+t \varepsilon_{\theta}^{l}(\theta)\right)+s L(\theta) H(\tau)\left(\left(1-\frac{t^{*}}{\theta} \varepsilon^{l}(\theta)\right)(1-\right. \\
& =-\frac{s e^{*}}{\theta^{2}} r H\left(T \varepsilon^{l}(\theta)+t \varepsilon_{\theta}^{l}(\theta)\right) .
\end{aligned}
$$

Hence $\varepsilon_{\theta}^{l}(\theta)>0$ implies $\frac{d \tau}{d s}>0$.

We can then conclude that $\varepsilon_{\tau}^{h}\left(\tau^{*}\right)>0$ and $\varepsilon_{\theta}^{l}(\theta)>0$ guarantee both the SOC and $\frac{d \tau}{d s}>0$ and $\frac{d t}{d s}>0$. Furthermore, as at the equilibrium, both elasticities are strictly smaller than one, this finally implies by the government's budget constraint $\frac{d e}{d s}<0$.QED

For future reference, let us define with $w(T, s)=u\left(\tau^{*}(s, T), t^{*}(s, T), T\right)+E-\frac{s}{2} e^{*}(s, T)^{2}$ the maximum utility that a government of type $s$ could get when the central tax rate is $T$ - By differentiating the FOC above and invoking the envelope theorem, it is easy to show $\partial w(T, s) / \partial T<0$; both types are worse off when the central government sets a higher tax rate.

Consider then the first period. Suppose first that the central government has set $\underline{T}$ for the first period. The incompetent Mayor could play the fully pooling strategy $\left(\tau^{*}(\underline{s}, \underline{T}), t^{*}(\underline{s}, \underline{T})\right)$ the partial pooling strategy $\left(\tau^{*}(\underline{s}, \bar{T}), \widetilde{t}=\bar{T}-\underline{T}+t(\underline{s}, \bar{T})\right)$ or the separating strategy $(($ $\left.\tau^{*}(\bar{s}, \underline{T}), t^{*}(\bar{s}, \underline{T})\right)$, in all cases setting up $e$ so as to satisfy the budget constraint. If the partial pooling strategy is played, substituting in the budget constraint, we get that the effort that the incompetent Mayor needs to offer to provide the services in this case, $\widetilde{e}$ :

$$
\begin{gathered}
\widetilde{e}=1-\widetilde{t} L(\bar{T}+t(\underline{s}, \bar{T}))-\tau(\underline{s}, \bar{T}) H(\tau(\underline{s}, \bar{T})) \\
\widetilde{e}=1-t(\underline{s}, \bar{T}) L(\bar{T}+t(\underline{s}, \bar{T}))-\tau(\underline{s}, \bar{T}) H(\tau(\underline{s}, \bar{T}))-(\bar{T}-\underline{T}) L(\bar{T}+t(\underline{s}, \bar{T}))
\end{gathered}
$$

Which finally implies:

$$
e(\underline{s}, \bar{T})-\widetilde{e}=(\bar{T}-\underline{T}) L(\bar{T}+t(\underline{s}, \bar{T}))>0
$$


as stated into the text.

Let us then define with $-\Delta w_{2}(T)=u\left(\tau^{*}(\underline{s}, T), t^{*}(\underline{s}, T), T\right)-\frac{\bar{s}}{2}\left(e^{*}(\underline{s}, T)\right)^{2}-w(T, \bar{s})<0$ the first period loss that the incompetent Mayor would suffer by playing the fully pooling strategy when the central tax rate is $T$. Using this expression, the utility loss for the incompetent Mayor in the first period if he plays the partial pooling strategy and pretends $T=\bar{T}$ while $T=\underline{T}$ was in fact chosen, call it $-\Delta \widetilde{w}_{2}(\bar{T} ; \underline{T})$, can be written as:

$$
-\Delta \widetilde{w}_{2}(\bar{T} ; \underline{T})=-\Delta w_{2}(\bar{T})+(w(\bar{s}, \bar{T})-w(\bar{s}, \underline{T}))+\frac{\bar{s}}{2}\left(\left(e^{*}(\underline{s}, \bar{T})\right)^{2}-\widetilde{e}^{2}\right)
$$

Subtracting $-\Delta w_{2}(\underline{T})$ from $-\Delta \widetilde{w}_{2}(\bar{T} ; \underline{T})$, it follows that if the condition

$$
\text { (*) } \Delta w_{2}(\underline{T})-\Delta \widetilde{w}_{2}(\bar{T} ; \underline{T})>0
$$

is satisfied, the incompetent Mayor is better off in terms of first period losses by playing the partial pooling strategy rather than the fully pooling one. We now prove:

Lemma If $\frac{\bar{s}}{\underline{s}}<\widehat{s},(*)$ is violated, and if $\frac{\bar{s}}{\underline{s}}>\widehat{s},(*)$ is satisfied.

Rewriting, condition $(*)$ can also be written as

$$
\begin{gathered}
u\left(\tau^{*}(\underline{s}, \bar{T}), t^{*}(\underline{s}, \bar{T}), \bar{T}\right)-u\left(\tau^{*}(\underline{s}, \underline{T}), t^{*}(\underline{s}, \underline{T}), \underline{T}\right)+\frac{\bar{s}}{2}\left(e^{*}(\underline{s}, \underline{T})^{2}-(\widetilde{e})^{2}\right)>0 \\
=u\left(\tau^{*}(\underline{s}, \bar{T}), t^{*}(\underline{s}, \bar{T}), \bar{T}\right)-u\left(\tau^{*}(\underline{s}, \underline{T}), t^{*}(\underline{s}, \underline{T}), \underline{T}\right)+\frac{\bar{s}}{2}\left(\left(e^{*}(\underline{s}, \underline{T})+(\widetilde{e})\right)\left(e^{*}(\underline{s}, \underline{T})-(\widetilde{e})\right)\right)>0
\end{gathered}
$$

note that

$$
e^{*}(\underline{s}, \underline{T})-\widetilde{e}=e^{*}(\underline{s}, \underline{T})-e(\underline{s}, \bar{T})+(\bar{T}-\underline{T}) L(\bar{T}+t(\underline{s}, \bar{T}))
$$

applying a FO Taylor approximation:

$$
e^{*}(\underline{s}, \underline{T})-e(\underline{s}, \bar{T}) \approx t L^{\prime}(\bar{T}+t(\underline{s}, \bar{T})) \Delta T
$$

where $\Delta T=\bar{T}-\underline{T}>0$. It follows;

$$
e^{*}(\underline{s}, \underline{T})-\widetilde{e} \approx\left(L(\bar{T}+t(\underline{s}, \bar{T}))+t L^{\prime}(\bar{T}+t(\underline{s}, \bar{T}))\right) \Delta T=\bar{L}\left(1-\frac{\bar{t}}{\bar{\theta}} \varepsilon^{l}(\bar{\theta})\right) \Delta T>0
$$


where

$$
\begin{gathered}
\bar{L}=L(\bar{T}+t(\underline{s}, \bar{T})), \bar{t}=t(\underline{s}, \bar{T}) \\
\bar{\theta}=\bar{T}+t(\underline{s}, \bar{T})
\end{gathered}
$$

Similarly, invoking the FOC for government maximization:

$$
u\left(\tau^{*}(\underline{s}, \bar{T}), t^{*}(\underline{s}, \bar{T}), \bar{T}\right)-u\left(\tau^{*}(\underline{s}, \underline{T}), t^{*}(\underline{s}, \underline{T}), \underline{T}\right) \approx-\bar{L} \Delta T
$$

Note further by the FOC for government maximization

$$
-\bar{L}=-\underline{s} e(\bar{T}, \underline{s}) \bar{L}\left(\left(1-\frac{\bar{t}}{\bar{\theta}} \varepsilon^{l}(\bar{\theta})\right)\right.
$$

substituting we finally get:

$$
\Delta w_{2}(\underline{T})-\Delta \widetilde{w}_{2}(\bar{T} ; \underline{T}) \approx \frac{1}{2} \Delta T \bar{L}\left(\left(1-\frac{\bar{t}}{\bar{\theta}} \varepsilon^{l}(\bar{\theta})\right)(\bar{s}((e(\underline{s}, \underline{T})+(\widetilde{e}))-\underline{s} 2 e(\underline{s}, \bar{T}))\right.
$$

now note that

$$
2 e(\underline{s}, \bar{T})>e(\underline{s}, \underline{T})+\widetilde{e}
$$

and recall that $\bar{s}>\underline{s}$. The sign of $(*)$ is then generally uncertain. In particular, $(*)$ is violated if $\bar{s} \leq s^{*}$ and $(*)$ is satisfied if $\bar{s}>s^{*}$, where $s^{*}=\underline{s} \frac{2 e(\underline{s}, \bar{T})}{e(\underline{s}, \underline{T})+\widetilde{e}}$. Thus, if $\underline{\underline{s}}>\frac{2 e(\underline{s}, \bar{T})}{e(\underline{s}, \underline{T})+\widetilde{e}}=\widehat{s}$ condition $(*)$ is satisfied. QED.

Equilibria with the surcharge tax on income

Even if condition $(*)$ is satisfied, this is still not a sufficient condition for the incompetent Mayor to be willing to play the partial pooling strategy. This also depends on the probability of being re-elected if he plays this strategy. At a partial pooling equilibrium, the rational voter will of course be able to predict correctly the equilibrium strategy of the incompetent Mayor. This implies, by Bayes' rule, that by observing $\bar{\theta}=\bar{T}+t(\underline{s}, \bar{T})$ and $\bar{\tau}=\tau(\underline{s}, \bar{T})$, the voter's revised beliefs on the type of government, $\mu(\theta, \tau)$ will be given by:

$$
\mu(\bar{\theta}, \bar{\tau})=\frac{q \pi}{q \pi+(1-q)(1-\pi)}
$$

It follows that voters will re-elect the incompetent Mayor if $\mu(\theta, \tau) \geq q$ or if $\pi \geq \frac{1}{2}$, which in our case is true by assumption. Finally, the incompetent Mayor will play the partial pooling equilibrium rather than deviate and play his preferred strategy if: 


$$
\delta \geq \frac{\Delta \widetilde{w}_{2}(\bar{T} ; \underline{T})}{\xi w(\bar{s}, T)+E} \equiv k_{3}(\bar{T}) .
$$

where $\xi$ is the expectation operator and where expectations are based on the realization of $T$ in the second period. Assuming that the condition $(*)$ is satisfied and $\delta \geq k_{3}(\bar{T})$, playing the partial pooling strategy is the best strategy for the incompetent Mayor. There is no reason for him to deviate and play the fully pooling strategy instead because whatever the beliefs of the voter upon observing $\underline{\theta}=\underline{T}+t(\underline{s}, \underline{T})$ and $\underline{\tau}=\tau(\underline{s}, \underline{T})$, this will not give the incompetent Mayor a better chance of re-election; and furthermore the fully pooling strategy produces a higher first period welfare loss. Moreover, there is no reason for him to play his preferred strategy as this would lead to sure defeat at the elections and the condition $\delta \geq k_{3}(\bar{T})$ guarantees that the first period loss of the partial pooling strategy is dominated by the future expected benefit.

Suppose instead that the Central government has played $\bar{T}$. As is easy to check, it would not make sense for the incompetent Mayor to play the partial pooling strategy (pretending that instead $\underline{T}$ has been played), because by Bayes' rule, $\pi \geq \frac{1}{2}$ implies that the incompetent Mayor would not be re-elected by playing the partial pooling strategy in this case: thus, the incompetent Mayor would be better off by playing his preferred strategy in the first period too. The incompetent Mayor could instead play the fully pooling strategy $\left(\tau^{*}(\underline{s}, \bar{T}), t^{*}(\underline{s}, \bar{T})\right)$

and set the effort level so as to satisfy the budget constraint. Note that at this Bayesian equilibrium, as both types play the same strategy, the rational consumer would not learn anything by observing the tax choices and would therefore assign the same ex ante probability of the Mayor being competent (that is, $q$ ) and then re-elect him. Hence, the incompetent Mayor will play the fully pooling strategy if

$$
\delta \geq \frac{\Delta w_{2}(\bar{T})}{\xi(w(\bar{s}, T))+E} \equiv k_{2}(\bar{T})
$$

where

$$
-\Delta w_{2}\left(\overline{T)}=u\left(\tau ^ { * } \left(\underline{s}, \overline{T)}, t^{*}(\underline{s}, \overline{T)}, \bar{T})-\frac{\bar{s}}{2}\left(e^{*}(\underline{s}, \bar{T})\right)^{2}-w(\bar{T}, \bar{s})<0\right.\right.\right.
$$

We are then ready to prove Proposition 2.

\section{Proof of proposition 2}

By the analysis above, we know that if $\delta \geq k_{2}(\bar{T})$ and the national government selects $\bar{T}$ in the first period, there exists a fully pooling equilibrium in pure strategies, where the incompetent Mayor just replicates in the first period the choices of the competent Mayor for $T=\bar{T}$. Notice that this equilibrium is robust to all possible deviations. $\delta \geq k_{2}(\bar{T})$ guarantees that the incompetent Mayor is better off by playing the fully pooling strategy 
rather than selecting his preferred strategy, as this would lead to sure defeat in the elections, and $\delta \geq k_{2}(\bar{T})$ guarantees that his first period losses from playing the fully pooling strategy are more than compensated by the re-election. When $T=\bar{T}$ the fully pooling strategy also dominates the partial pooling strategy. If instead the central government sets $T=\underline{T}$ , we know from the analysis in the text that providing that condition $(*)$ is satisfied and $\delta \geq k_{3}(\bar{T})$, there exists a partial pooling equilibrium where the incompetent Mayor plays $(\bar{\theta}, \bar{\tau})$ in the first period and it is then re-elected for sure. Finally, one might ask if a fully pooling equilibrium exists when $T=\underline{T}$ and $\delta \geq k_{2}(\underline{T})$. At the proposed equilibrium, only the competent government would play $\left(\tau^{*}(\underline{s}, \underline{T}), t^{*}(\underline{s}, \underline{T})\right)$ and therefore the consumer would re-elect this government, thus providing an incentive for the incompetent Mayor to deviate to this strategy, playing the full pooling strategy. However, providing that condition $(*)$ is satisfied, it this equilibrium is not robust to a deviation to the partial pooling strategy, where the incompetent Mayor plays $(\bar{\theta}, \bar{\tau})$ instead. When more than a perfect Bayesian equilibrium is an effect, the rational voter may be confused on which equilibrium strategies are effectively being played. If by observing $(\bar{\theta}, \bar{\tau})$ in the first period, the voter believes that either the partial pooling equilibrium at $(\bar{\theta}, \bar{\tau})$ is played or the fully pooling equilibrium at $(\bar{\theta}, \bar{\tau})$ is played, he would then rationally re-elect the incumbent Mayor. But then, as by condition $(*)$ the first period losses under the partial pooling equilibrium are lower than under the full pooling equilibrium when $T=\underline{T}$, the incompetent Mayor would now have a profitable deviation which would destroy the fully pooling equilibrium at $T=\underline{T}$. Finally note that condition (*) implies that $k_{2}(\underline{T})>k_{3}(\bar{T})$; hence, for $k_{2}(\underline{T})>\delta \geq k_{3}(\overline{\bar{T}})$, there exists no full pooling strategy at $T=\underline{T}$ while it does exist a partial pooling equilibrium. QED

\section{Proof of the Corollary}

Repeating the previous analysis and assuming that the consumer observes $T$, the conditions for pooling in the case $\underline{T}$ would become

$$
\delta \geq \frac{\Delta w_{2}(\underline{T})}{\xi(w(\bar{s}, T))+E} \equiv k_{2}(\underline{T})
$$

where $\Delta w_{2}(\underline{T})=-u\left(\tau^{*}(\underline{s}, \underline{T}), t^{*}(\underline{s}, \underline{T}), \underline{T}\right)+\frac{\bar{s}}{2}\left(e^{*}(\underline{s}, \underline{T})\right)^{2}+w(\underline{T}, \bar{s})$

But condition $(*)$ immediately implies $k_{2}(\underline{T})>k_{3}(\bar{T})$. QED

Finally, note by comparing $k_{1}(T)$ with $k_{2}(T)$, that $k_{1}(T) \geq k_{2}(T)$ is also likely to be true. ${ }^{22}$ By a revealed preference argument, the expected utility of being re-elected is certainly larger when the Mayor can introduce a surcharge tax on income (as he can always set this surcharge equal to zero and with that replicate the choice without the surcharge), implying that the denominator in the equation defining $k_{2}(T)$ is at least as large as the denominator in the equation defining $k_{1}(T)$. Hence, unless $\Delta w_{2}(T)$ is also larger than $\Delta w_{1}(T)$ (and generally there is no reason why this would be the case), we should also expect $k_{2}(T)$ to be smaller

\footnotetext{
${ }^{22}$ In the equation defining $K_{1}$, for simplicity, we did not consider the dependence of $K_{1}$ on the realization of $\theta$. Observe that $\theta=T$ when the Mayor cannot introduce a surcharge tax. Reintroducing it and considering the uncertainty surrounding the choice of $T$ by the central government in the second period, the comparative static argument discussed into the text becomes obvious.
} 
than $k_{1}(T)$. Combining this observation with the corollary above, our general conclusion is that the introduction of the PIT surcharge should have the effect of increasing pooling behavior, allowing incompetent Mayors to mimic competent ones in a larger set of cases. 


\section{Online Appendix 2}

\section{Variable Definitions}

1. Residence property tax:Introduced in 1993 (Law Decree 30-12-1992 n. 504), Municipal property tax on real estate is set up on a yearly base. The tax base is fixed at the level determined by the cadastral survey (relative to early 90's and revised only rarely) and differentiated according to a classification based on the discrimination between residential and commercial or business. The range of municipal property tax rates is restricted to lie in the interval from a minimum of $0.4 \%$ up to a maximum of $0.7 \%$. Source: Ministry of Interior municipal balance sheets and ANCI, Italian municipal association IFEL.

2. Deductions:Municipalities can introduce specific deductions for resident owners. We have the information on the total amount in 2012 Euro of deductions and we normalize them on the resident population.Source: ANCI, Italian municipal association IFEL.

3. Business property tax: Business property tax is applied to commercial or business property category. This tax base includes factories and warehouses and other buildings used for productive activity. It is also applied to dwellings not owned by residents. A very small part of the business tax base is rural and building land. Tax rates lie in the range $0.4-0.7 \%$. The weight of Business property tax revenues is approximately $70 \%$ of the total property revenues (2006 Ministry of Interior data). Source: Ministry of Interior municipal balance sheets and ANCI, Italian municipal association.

4. Personal income tax (PIT) surcharge: Introduced in 1999, its base is the total taxable income declared locally. It works like a sort of ad valorem tax, as it extracts a percentage determined yearly from the tax base. As for the Personal Income Tax (PIT) Surcharge, the range of intervention goes from a minimum of $0 \%$ to a maximum of $0.5 \%$ (up to $0.8 \%$ in 2007). PIT tax revenues are drawn from municipal balance sheet. Source: Ministry of Interior municipal balance sheets.

5. Population data: municipal resident population collected as of 31 December of each year by Italian National Statistical Office (ISTAT).

- Population density: resident population out of the square kilometers of the municipality.

- Young: residents 0-14 out of the total residents per municipality.

- Old: residents older than 65 out of the total residents per municipality.

6. Transfers: total current transfer from upper levels of government (Central government and the Regional Government). Per capita transfers used in estimates were deflated using national CPI in 2012 euro. Source: Ministry of Interior municipal balance sheets. 
7. Treated/Control:Treated are the municipalities where the mayors can be re-elected and Control are the municipalities where mayors are subject to term limit.

8. No Profit Organizations:the number of nonprofit organizations per capita at the provincial level (from the 2001 Census).

9. Daily Newspapers:the diffusion of non-sport newspapers every 100 inhabitants at the provincial level (source: Cartocci 2007).

10. Size: It is the municipality size based on the resident population.

11. $\mathbf{R S O} / \mathbf{R S S}: R S O=$ region with ordinary statute; $R S S$ : regions with special statutes.

\begin{tabular}{|c|c|c|c|}
\hline \multicolumn{4}{|c|}{ Descriptives } \\
\hline Variable & Obs & Mean & Std. Dev. \\
\hline \multicolumn{4}{|l|}{ Panel A: All } \\
\hline Resident Tax & 77,941 & 5.178407 & 0.6900285 \\
\hline Business Tax & 79,182 & 5.618385 & 0.8142774 \\
\hline Resident Tax Deductions & 77,461 & 2.46274 & 1.186683 \\
\hline PIT surcharge Tax & 79,182 & 0.0957856 & 0.162609 \\
\hline PIT Surcharge Revenues & 27,566 & 3.083831 & 0.708691 \\
\hline Population Density & 79,182 & 347.3373 & 3047.784 \\
\hline Young & 79,182 & 0.1341463 & 0.0383858 \\
\hline Old & 79,182 & 0.2122851 & 0.0672717 \\
\hline Transfers & 7,9089 & 237.9059 & 233.0024 \\
\hline \multicolumn{4}{|c|}{ Panel B: Only 2 mandates } \\
\hline Resident Tax & 45,631 & 5.178537 & 0.6785977 \\
\hline Business Tax & 46,356 & 5.592605 & 0.7986081 \\
\hline Resident Tax Deductions & 45,308 & 2.479811 & 1.1375 \\
\hline PIT surcharge Tax & 46,356 & 0.0921988 & 0.1579854 \\
\hline PIT Surcharge Revenues & 15,182 & 3.038314 & 0.7203144 \\
\hline Population Density & 46,356 & 342.9355 & 3225.972 \\
\hline Young & 46,356 & 0.1325693 & 0.0369145 \\
\hline Old & 46,356 & 0.2134098 & 0.0665516 \\
\hline Transfers & 46,283 & 239.6401 & 236.988 \\
\hline
\end{tabular}


1. L. Colombo, H. Dawid, Strategic Location Choice under Dynamic Oligopolistic Competition and Spillovers, Novembre 2013.

2. M. Bordignon, M. Gamalerio, G. Turati, Decentralization, Vertical Fiscal Imbalance, and Political Selection, Novembre 2013.

3. M. Guerini, Is the Friedman Rule Stabilizing? Some Unpleasant Results in a Heterogeneous Expectations Framework, Novembre 2013.

4. E. Brenna, C. Di Novi, Is caring for elderly parents detrimental to women's mental health? The influence of the European North-South gradient, Novembre 2013.

5. F. Sobbrio, Citizen-Editors' Endogenous Information Acquisition and News Accuracy, Novembre 2013.

6. P. Bingley, L. Cappellari, Correlation of Brothers Earnings and Intergenerational Transmission, Novembre 2013.

7. T. Assenza, W. A. Brock, C. H. Hommes, Animal Spirits, Heterogeneous Expectations and the Emergence of Booms and Busts, Dicembre 2013.

8. D. Parisi, Is There Room for 'Fear' as a Human Passion in the Work by Adam Smith?, Gennaio 2014.

9. E. Brenna, F. Spandonaro, Does federalism induce patients' mobility across regions? Evidence from the Italian experience, Febbraio 2014.

10. A. Monticini, F. Ravazzolo, Forecasting the intraday market price of money, Febbraio 2014.

11. Tiziana Assenza, Jakob Grazzini, Cars Hommes, Domenico Massaro, $P Q$ Strategies in Monopolistic Competition: Some Insights from the Lab, Marzo 2014.

12. R. Davidson, A. Monticini, Heteroskedasticity-and-Autocorrelation-Consistent Bootstrapping, Marzo 2014.

13. C. Lucifora, S. Moriconi, Policy Myopia and Labour Market Institutions, Giugno 2014.

14. N. Pecora, A. Spelta, Shareholding Network in the Euro Area Banking Market, Giugno 2014.

15. G. Mazzolini, The economic consequences of accidents at work, Giugno 2014.

16. M. Ambrosanio, P. Balduzzi, M. Bordignon, Economic crisis and fiscal federalism in Italy, Settembre 2014.

17. P. Bingley, L. Cappellari, K. Tatsiramos, Family, Community and Long-Term Earnings Inequality, Ottobre 2014.

18. S. Frazzoni, M. L. Mancusi, Z. Rotondi, M. Sobrero, A. Vezzulli, Innovation and export in SMEs: the role of relationship banking, Novembre 2014.

19. H. Gnutzmann, Price Discrimination in Asymmetric Industries: Implications for Competition and Welfare, Novembre 2014.

20. A. Baglioni, A. Boitani, M. Bordignon, Labor mobility and fiscal policy in a currency union, Novembre 2014.

21. C. Nielsen, Rational Overconfidence and Social Security, Dicembre 2014.

22. M. Kurz, M. Motolese, G. Piccillo, H. Wu, Monetary Policy with Diverse Private Expectations, Febbraio 2015.

23. S. Piccolo, P. Tedeschi, G. Ursino, How Limiting Deceptive Practices Harms Consumers, Maggio 2015.

24. A.K.S. Chand, S. Currarini, G. Ursino, Cheap Talk with Correlated Signals, Maggio 2015. 
25. S. Piccolo, P. Tedeschi, G. Ursino, Deceptive Advertising with Rational Buyers, Giugno 2015.

26. S. Piccolo, E. Tarantino, G. Ursino, The Value of Transparency in Multidivisional Firms, Giugno 2015.

27. G. Ursino, Supply Chain Control: a Theory of Vertical Integration, Giugno 2015.

28. I. Aldasoro, D. Delli Gatti, E. Faia, Bank Networks: Contagion, Systemic Risk and Prudential Policy, Luglio 2015.

29. S. Moriconi, G. Peri, Country-Specific Preferences and Employment Rates in Europe, Settembre 2015.

30. R. Crinò, L. Ogliari, Financial Frictions, Product Quality, and International Trade, Settembre 2015.

31. J. Grazzini, A. Spelta, An empirical analysis of the global input-output network and its evolution, Ottobre 2015.

32. L. Cappellari, A. Di Paolo, Bilingual Schooling and Earnings: Evidence from a Languagein-Education Reform, Novembre 2015.

33. A. Litina, S. Moriconi, S. Zanaj, The Cultural Transmission of Environmental Preferences: Evidence from International Migration, Novembre 2015.

34. S. Moriconi, P. M. Picard, S. Zanaj, Commodity Taxation and Regulatory Competition, Novembre 2015.

35. M. Bordignon, V. Grembi, S. Piazza, Who do you blame in local finance? An analysis of municipal financing in Italy, dicembre 2015. 